\title{
"To Carve Nature at Its Joints": On the Existence of Discrete Classes in Personality
}

\author{
Steve Gangestad and Mark Snyder \\ University of Minnesota
}

\begin{abstract}
In principle, units of personality may be of two varieties: dimensional variables, which involve continuously distributed differences in degree, and class variables, which involve discretely distributed differences in kind. There exists, however, a prevailing and rarely questioned assumption that the units of personality are continuous dimensions and an accompanying prejudice against class variables. We examine this prejudice, the arguments that generated it, and those that uphold it. We conclude that these arguments are applicable to class variables as they often have been explicated, in phenetic terms; by contrast, genetically explicated class variables are not vulnerable to these arguments. We propose criteria for conjecturing and present methods for corroborating the existence of class variables in personality. Specifically, we test a class model of a construct whose conceptual status makes it reasonable to evaluate whether or not the differences between individuals represented by this construct constitute discrete classes. Finally, we examine the implications for conceptualizing and investigating the nature and origins of personality.
\end{abstract}

As a psychological concept, personality refers to regularities and consistencies in the behavior of individuals and to structures and processes that underlie these regularities and consistencies. Such phenomena, to the extent that they exist, ought to distinguish individuals from other individuals and to render their actions predictable. Typically, in personality theories, these distinguishing features have been treated as comparative individual differences on the assumption that one can mean-

The research and preparation of this manuscript were supported in part by National Science Foundation Grant BNS 82-07632 to Mark Snyder, in part by a National Science Foundation Graduate Fellowship to Steve Gangestad, and in part by a grant from the University of Minnesota Computer Center.

We are grateful to Auke Tellegen for recommending the Monte Carlo simulation and valuable additional external validation analyses; in addition, he and Allan $R$. Harkness provided helpful advice on conducting the simulation. Also, we thank Jeffry A. Simpson for assisting in the empirical phase of the real variable control. Finally, we appreciate the constructive comments of Paul E. Meehl, Auke Tellegen, Jack Block, William G. Graziano, Allan R. Harkness, Jeffry A. Simpson, Dave Smith, and Jason Young.

Requests for reprints should be sent to Steve Gangestad or Mark Snyder, Department of Psychology, University of Minnesota, 75 East River Road, Minneapolis, Minnesota 55455 . ingfully compare any two individuals in terms of the same variables.

In principle, these personality variables may be of at least two varieties. On the one hand, there are dimensions or characteristics thought to be possessed in some quantitative degree by all individuals. As a result, the distributions of such characteristics are continuous ones. Dimensions hardly need further introduction; they are well-known in the traditional vocabulary of personologists as traits. Indeed, most existing comprehensive personality inventories purport to measure the basic dimensions of personality. For instance, dominance is a putative trait, assumed to be distributed continuously and measured by one of the scales of the Personality Research Form (Jackson, 1974).

On the other hand, certain units of personality may not be dimensions, but rather, class variables. Class variables are expressed not continuously, but as differences distributed into discrete categories, and thus are differences that can be introduced by the colloquialism "There are two (or, for that matter, any finite number of ) types of people in the world." That is, when it comes to personality, class variables seek, as Plato put it, "to carve nature at its joints" by identifying true discretenesses in personality. 
If comparative individual differences can be distributed either as continuous dimensions or as discrete classes, then we may ask whether any specific difference between individuals is properly conceptualized as a dimension or a class variable. Is, for instance, extraversion a continuous dimension, possessed in some degree by all individuals (e.g., Eysenck, 1953), or a class variable, with individuals belonging either to the discrete class of extraverts or to that of introverts (e.g., Myers, 1962)? A little reflection, however, reveals that the appropriate roles of continuous dimensions and discrete classes in personality rarely ever surfaces as an issue for theoretical or empirical inquiry. The reason, it seems, is that this fundamental issue is almost universally a prejudged one. With few exceptions, the prejudgment is one captured by a statement borrowed from Milton: "Differing but in degree, of kind the same." Overwhelmingly, the basic units of personality are presumed to be dimensions.

In this article, we first examine this prejudgment, the arguments that generated it and those that uphold it. We conclude that there are cogent arguments against class variables as they have commonly been explicated. We next discuss a different explication of class variables, one that is not vulnerable to these same arguments. We then propose criteria for conjecturing and methods for corroborating the existence of class variables in personality. Specifically, we test a class model of a construct whose conceptual evolution makes it reasonable to evaluate whether it identifies discrete classes of individuals. Finally, we examine implications of class models for understanding the nature and the origins of personality.

\section{Presumption of Dimensionalism and the Prejudice Against Class Variables}

Most personologists immediately recognize that the presumption of dimensionalism is no straw person. One need not look far to find explicit statements of the preferred status of continuous dimensions, for example, the assertion that

The method of choice in personality scale construction is one which focuses on a linear relation between items and a single underlying latent continuum. Other approaches, embodying more complicated models such as class models have the status of curiosities (Jackson, 1971, p. 239).

Neither is it difficult to find explicit statements of prejudice against class variables, for instance:

In a course at the New School for Social Research, Muhammed Ali was reputed to offer this typology: People come in four types, the pomegranate (hard on the outside, hard on the inside), the walnut (hard-soft), the prune (soft-hard), and the grape (soft-soft). As typologies go, it's not bad-certainly there is no empirical reason to think it any worse than those we may be tempted to take more seriously (Mendelsohn, Weiss, \& Feimer, 1982, p. 1169).

Of course, some typologies do tempt one to take them seriously. Oddly enough, however, some of their proponents endorse a dimensional view of personality, not proposing the existence of true discrete categories, but claiming only that their proposed types reflect extreme ends of continuous distributions. For example, in Eysenck's (1953) typology of extraversion and introversion, each type exists only as an idealization defined by a cluster of attributes. Few, if any, individuals are thought to perfectly fit either idealization. Instead, Eysenck assumed that individuals can be assessed, for degree of fit to each of the ideals, along a continuous dimension.

Several classic typologies-such as those of Jung (1921/1923) and Kretschmer (1948)also may be construed to postulate dimensional variables rather than true classes (cf. Eysenck, 1953). Thus, Jung (1921/1923) wrote, "Hence, there can never occur a pure type in the sense that he is entirely possessed of the mechanisms with complete atrophy of the other. A typical attitude signifies the mere relative predominance of one mechanism" (p. 9). And, contemporary theorists have regarded typologies as idealized concepts or theoretical fictions, whose usefulness is derived from "heuristic value rather than . . . relation to real world examples" (Hogan, 1983, p. 61 ). Seldom is any real discreteness claimed. It is thus difficult to argue with the claim that, "The widespread notion that typologies imply discontinuities, bimodal distributions, and the like, does not accurately reflect the writings of modern typologists" (Eysenck, 1969, p. 17).

It appears, then, that even typologically oriented personologists have joined with their 
nontypologist counterparts in the presumption that personality units come in quantitative degrees, rather than in true, discrete classes. Of course, this presumption is not necessarily unjustified. It is substantively justified to the extent that theoretical or empirical considerations yield the conclusion that real class variables simply are not to be found in personality. Accordingly, we ask: What might constitute such considerations?

\section{Arguments Against Class Variables}

Some of these arguments can be traced to traditions in the measurement of psychological properties (cf. Tyler, 1965). Sophisticated measurement methods were first developed for cognitive abilities assumed to be quantitative variables and, thus, are heavily steeped in dimensional analysis. Development of methods for measuring class variables, by contrast, proceeded more slowly (cf. Loevinger, 1957). As a result, methods for test construction and evaluation generally assume underlying latent continua, and personality researchers who adopt these methods may also adopt, without question, the underlying assumption of dimensionality.

Factor analysis presents a similar situation. Although not restricted by an assumption that factors are continuously distributed dimensional variables, the method has become associated with uncovering basic dimensions, not class variables, and thus factors are typically interpreted as dimensions. Thurstone (1947) himself encouraged this association: "The factors in psychological investigations are not ordinarily to be thought of as elemental things which are present or absent, like heads or tails in the tossing of coins" (p. 56). Hence, many factor analysts who believe they are uncovering primary units of personality also believe these primary units are dimensions.

These statistical traditions may be responsible for a methodological inertia that creates an unfavorable environment for class models of personality. There may, however, exist a more fundamental and pervasive reason why the search for continuous dimensions has become the "method of choice" in personality. This reason, we suspect, is a fundamental distrust of class variables ingrained in the traditions of North American personality theory, a distrust rooted in the following (or some similar) argument. The minor premise of this argument states that generally we can measure basic, low-level, phenotypic characteristics of personality on continuously distributed dimensions. If so, the major premise states, to propose the existence of discrete classes in personality is bound to be an oversimplification or, worse yet, an entirely arbitrary fiction. Thus, one personality theorist has asserted that "simplicity limits their (class variables') value. Generally, an individual's behaviors are so complex, diverse, and variable that he cannot be sorted into a simplistic category or slot" (Mischel, 1976; p. 16). And, in a related vein, others have argued that "Because personality variables are distributed continuously and are inevitably subject to consensual definitions, personality types are bound to be arbitrary constructions rather than discoveries of how to 'carve nature at its joints'" (Mendelsohn et al., 1982, pp. 1168-1 169).

But just how cogent are these arguments? Are class variables really unable to deliver on their promise "to carve nature at its joints"? The answer to this question depends critically on what form of classification system is under scrutiny. We may distinguish between two general approaches to classification, only one of which is vulnerable to criticisms of oversimplification and arbitrariness. The other approach-which is not so readily dismissed as leading to, at best, oversimplifications and, at worst, arbitrary fictions-may make it possible to assert the genuine existence of discrete classes in personality.

\section{Approaches to Classification: Phenetic and Genetic Explications}

One approach has been explicated phenetically (e.g., Gingerich, 1979; McNeill, 1979; Ruse, 1973; Sneath \& Sokal, 1973), with classes defined by covarying phenotypic (observable and first-order dispositional) characteristics that, when considered in a multidimensional phenotypic hyperspace, demonstrate densification or multimodality. The question the pheneticist asks, in effect, is "How can I reduce the information in the phenotypic hyperspace to a few categories 
such that similarity between personalities within categories is maximized and differences between personalities between categories is maximized?" This classification process is undertaken primarily for descriptive convenience, with the classification scheme serving a summarizing function. As such, no underlying meaning is directly ascribed to the constructed classes. Thus, one who asks what it means for individuals to belong to the same class simply will be told that they share relatively many common features in the clustered hyperspace. Examples of phenetic explication include attempts to delineate biological species, phyla, and kingdoms; and, within personality psychology, Cattell's types, defined as modes or central locations of densification in uni- or multidimensional spaces.

Probably, some notion of phenetic classification was what personologists (at least those we have quoted) had in mind when arguing against class variables. For, the case against phenetic explications of class variables in personality is a rather persuasive one. Phenotypic characteristics in personality may not cluster very tightly. Thus, classifications based on phenotypic characteristics may well be oversimplifications of the "real" state of affairs. And, given the multitude of currently available clustering methods based on different similarity indices that can yield quite different results, phenetic classifications in personality may be, if not arbitrary, at least quasi-arbitrary constructions (cf. Everitt, 1974).

We are, thus, sympathetic to the arguments against phenetically explicated class variables in personality, arguments to which the phenetic approach, by its very nature, may be intrinsically vulnerable (cf. Farris, 1979). But, there is a second approach to classification, one explicated in genotypic (rather than phenotypic) terms. In this approach, to say that a true class exists is to say that all members share some single genotypic source of influence upon their phenotypic characteristics. That is, a class exists when all members share some latent underlying entity, structure, or event that affects their current behavior or other outward characteristics. The phenotypic characteristics of the class members will, not incidentally, tend to be similar in domains where the common genotypic source is a causative influence, and this phenotypic covariation may be the basis for inferring the existence of the genotypic source. Nevertheless, in contrast to the phenetic approach, phenotypic similarity does not constitute the explicit definition of the classes. Rather, the latent genotypic class variable's nature is only implicitly defined by its causal relationship to the phenotypic characteristics. The latent class variable is instead defined as that something that must exist to explain the pattern of phenotypic covariation.

Viewed from the perspective of genetic explication (not to be strictly identified with biological genetics; Ashlock, 1979; Bock, 1973; Mayr, 1969; Meehl \& Golden, 1982), a class variable differs from a dimensional one in that the latent variable is thought to be distributed into discrete classes rather than along a continuous dimension. And, when explicated in the causal-theoretical terms of the genetic approach to classification, class variables simply are not subject to the criticisms that they represent oversimplifications of reality or that they are arbitrary constructions. Conjectured class variables explicated as latent constructs either really exist or they do not, and class variables explicated in these terms either really exercise influence upon phenotypic characteristics or they do not. That is, these class variables purport to identify real entities; truly, they purport "to carve nature at its joints." And we, at least, fail to see how entities that really exist and that exert real influences can represent oversimplifications or arbitrary constructions.

\section{Genetically Explicated Class Variables in Personality}

The genetic explication of class variables, we hasten to point out, should not be totally alien to personality psychologists. For, it simply identifies the class variable as a causaldispositional construct, one that refers to an underlying attribute or structure within the person conjectured to influence some domain of observable behavior (Cronbach \& Meehl, 1955; Loevinger, 1957). Moreover, this genetic explication of classification (which identifies class variables as causal-dispositional constructs) is highly compatible with one of the 
primary goals of personality (to identify underlying dispositional attributes that organize and structure behavior; cf. Snyder \& Ickes, 1985). Yet, to our knowledge, class variables in personality, with few exceptions, have been explicated not in terms of the causal-dispositional genetic approach, but instead in terms of phenotypic characteristics or as extreme values on dimensions. We suggest that, to understand why genetically explicated class variables have not emerged in personality theorizing, one must examine the etiology of personality variables.

Consider first the etiology of a continuous variable. The ideal conception of the continuous variable as normally distributed is justified if one believes numerous independent antecedent events have all contributed in small amounts to its development, that is, if we believe a many-trial Bernoulli process has generated the distribution of the variable (cf. Hays, 1973). Of course, this etiological model is an idealization. Nevertheless, when one infers the existence of a dimensional construct, one infers a latent variable that itself has been influenced by numerous quasi-independent causal events.

This diffuse process of etiology is to be expected if personality development conforms to many of the dominant models of developmental psychology. Of these, the most influential has been the environmental learning account (see, for instance, Mussen, Conger, \& Kagan, 1963). It proposes that generalized behavioral orientations develop across exposure to numerous relatively independent stimulus-response reinforcements, whose effects are continuously distributed dimensional characteristics. Other traditional accounts of development (those stressing imitation, identification, or observational learning; e.g., Bandura \& Walters, 1963) entail this same diffuse process of etiology. And, the predominant model within behavior genetics (the additive influence of alleles at multiple gene sites) also entails a diffuse etiology.

Class variables, however, are discretely distributed and, thus, the diffuse Bernoulli process is not a possible etiological model. Recently, Meehl (1977) outlined several models of specific etiology (which exists when a specific causal agent was present in the origins of an entity) for class variables. In its strongest sense, specific etiology refers to operation of a necessary and sufficient factor, or a necessary but not sufficient factor, which is itself a discrete entity. A somewhat weaker form of specific etiology is the threshold effect, which occurs when the class variable is caused by an underlying continuous variable dichotomized by some threshold, below which the variable exerts one effect, and above which it exerts another effect. These forms of specific etiology are largely incompatible with the views of personality development (emphasizing diffuse etiological processes) that have, at least until recently, dominated North American psychology. Nevertheless, at least two increasingly significant traditions, each of considerable relevance to developmental processes, could predict class variables in personality.

First, accumulating evidence suggests that genetic variation plays a significant, if not substantial, role in determining personality differences (e.g., Henderson, 1982; Plomin, DeFries, \& McClearn, 1980). Although it seems unlikely that any single Mendelizing gene has large effects on psychological parameters, more complex epistatic and polygenic threshold models can account for discretely distributed physiological parameters (e.g., Carter, 1969; Falconer, 1967). Quite possibly, these same models may account for discretely distributed psychobiological parameters having wide effects on individual and social behavior. Second, theoretical accounts of systematic and discontinuous structural changes during critical periods (e.g., Hall, 1907; Kohlberg, 1969; Piaget, 1965; Werner, 1957) are also compatible with the development of class variables. These discontinuous structural changes may occur differently for different individuals, dependent on thresholds of genetically or environmentally determined variables.

We do not deny the possibility that specific etiologies in personality may be rare events. It may well be that diffuse etiologies are the generally appropriate models of personality development (after all, they have served the purposes of developmental psychology for so long) and that specific etiologies are exceptions to the general case. Moreover, we recognize that, because of their possible rarity, some may choose to refer to class variables as 
curiosities. We, nonetheless, believe that, by virtue of their origins through specific rather than diffuse etiologies, class variables may represent especially intriguing and important psychological phenomena.

Admittedly, it still remains to be seen what, if any, particular class variables exert pervasive influences on human social behavior. Biological sex, a clear class variable, may have substantial impact on development; however, the precise domains of influence are still open to question (Block, 1976; Maccoby \& Jacklin, 1974). Several of the psychoses (e.g., schizophrenia; Meehl, 1962) have been conjectured to have underlying class variables as causes, but because their base rates are probably low, these class variables may not account for much variation in behavior in the general population. Let us now, then, address the critical issues of just how one goes about conjecturing and corroborating the existence of a class variable in personality.

\section{Conjecturing a Class Variable}

One may, of course, conjecture a class model of any personality construct one chooses. Nevertheless, one should have at least some minimal theoretical or empirical reasons to conjecture a class model before proceeding to test one. At least two kinds of reasons may suffice. First, one may have reason to believe that a particular specific etiology produces consistent behavioral manifestations. Such a reason provides an etiological springboard to a class model. Second, one may be aware of a theoretical network of contemporaneous causal relationships that specifies differences between individuals in kind rather than in degree, or that proposes that individuals possess discretely different internal structures that influence behavior. Such a reason constitutes a contemporaneoustheoretic springboard to a class model.

On the basis of these considerations, we were able to identify a personality construct that could be conjectured to exist as a class variable, and to demonstrate that differences between individuals in this conjectured class variable are distributed into discrete categories. The variable that we identified is one that is known to have wide-ranging influences on individual and social behavior. Not acci- dentally, it is one with which we are highly familiar. Specifically, we conjectured that a major source of variance underlying the responses to the Self-Monitoring Scale (Snyder, 1974) and accounting for a major portion of the extensive network of observed relations between responses to this measure and predicted criterion behaviors (see below and Snyder, 1979a, 1979b) is a dichotomous class variable.

According to theoretical analyses of selfmonitoring (the first propositions of which appeared in the mid 1970s; Snyder, 1974), individuals differ in the extent to which they monitor, through self-observation and selfcontrol, their expressive behavior and selfpresentation. Some individuals, those high in self-monitoring, are thought to regulate their expressive self-presentation for the sake of desired public appearances, and thus are thought to act in ways that are highly sensitive to social and interpersonal cues of situationally appropriate performances. Other individuals, those low in self-monitoring, are thought to lack either the ability or the motivation to so regulate their expressive self-presentation. They, instead, are thought to display expressive behavior that truly reflects their own attitudes, traits, feelings, and other current inner states.

A number of hypotheses follow from these basic initial propositions. Thus, for example, according to the self-monitoring construct, high self-monitoring individuals should be better able than low self-monitoring individuals to convincingly display a wide variety of emotions without actually experiencing the emotions. Furthermore, the behavior of high self-monitoring individuals should be more sensitive than that of low self-monitoring individuals to shifts in what constitutes "good" performance in a social situation. And, in behavioral domains where variation in what is socially appropriate across situations is great, high self-monitoring individuals should report greater behavioral variability across situations than should low self-monitoring individuals. By contrast, low self-monitoring individuals should exhibit greater consistency of behavioral expressions of feelings and thoughts expected to be stable, and thus they should show greater correspondence between self-report measures of attitudes and 
preferences and nontest behavioral indicators of these attitudes and preferences.

Research on self-monitoring, designed to test these and other hypotheses, typically has employed a 25-item true-false self-report measure to identify individuals high and low in self-monitoring. Sample items are "I would probably make a good actor," "I guess I put on a show to impress or entertain people," "I have trouble changing my behavior to suit different people and different situations," and "I would not change my opinions (or the way I do things) in order to please someone else or win their favor"; see Snyder, 1974, p. 531, for a complete list of the 25 items. In research using this measure, all of the hypotheses stated above, and many others, have received empirical support (e.g., Ajzen, Timko, \& White, 1982; Becherer \& Richard, 1978; Caldwell \& O'Reilly, 1982; Danheiser \& Graziano, 1982; Ickes, Layden, \& Barnes, 1978; Krauss, Geller, \& Olson, 1976; Kulik \& Taylor, 1981; Lippa, 1976, 1978a, 1978b; Lippa \& Mash, 1979; Lippa, Valdez, \& Jolly, 1979; Lutsky, Woodworth, \& Clayton, 1980; McCann \& Hancock, 1983; Paulhus, 1982; Rarick, Soldow, \& Geiser, 1976; Ross, McFarland, \& Fletcher, 1981; Shaffer, Smith, \& Tomarelli, 1982; Snyder, 1974; Snyder, Berscheid, \& Glick, 1985; Snyder \& Cantor, 1980; Snyder \& Gangestad, 1982; Snyder, Gangestad, \& Simpson, 1983; Snyder \& Kendzierski, 1982a, 1982b; Snyder \& Monson, 1975; Snyder \& Swann, 1976; Snyder \& Tanke, 1976; Tunnell, 1980; Tybout \& Scott, 1983; Zanna, Olson, \& Fazio, 1980; Zuckerman \& Reis, 1978). Further validation and extensions of the self-monitoring construct have been reviewed by Snyder (1979a, 1979b) and Shaw and Costanzo (1982).

From the perspective of construct validation (e.g., Cronbach \& Meehl, 1955), then, there appears to be strong evidence for the existence of a latent causal factor-as yet not directly observed-that partially accounts for a specifiable, yet extensive and extensible, domain of observable behavior and that we call the self-monitoring variable. More recently, attempts have been made to explicate the nature of this causal factor and the larger causal network within which it is embedded. Thus, for instance, Snyder and Campbell (1982) argued that individuals high and low in self- monitoring are guided by different metacontrols of behavior in social contexts. According to this view, the interactions of high self-monitoring individuals are guided by pragmatic organizing structures that lead one to consider the self's performances and the strategic appearances they generate. The interactions of low self-monitoring individuals, on the other hand, are purported to be guided by principled organizing structures that lead one to consider the consistency of the self's deeds with one's private world of beliefs and feelings.

These theoretical treatments implicitly suggest, then, that the organizing structures that guide the expressive behavior of individuals high and low in self-monitoring differ not in degree, but in kind. That is, within these treatments are hints that underlying self-monitoring propensities may be a causal factor that is discrete, not continuous, in nature. As such, these hints provide us with a contemporaneous-theoretic springboard for conjecturing a class variable. We thus have been led to ask the questions: Do there exist two classes of individuals that differ in selfmonitoring propensities, each homogeneous in the sense that the behavior of all individuals within the class is affected by a shared etiological entity? Does there exist a specific dichotomous etiological factor or threshold effect operating in the development and thus the eventual expression of these differing selfmonitoring propensities that organize expressive behavior?

\section{Evaluating the Class Model: Structural and External Components}

How does one distinguish variables that entail classes that are discrete, nonarbitrary, and real in nature from continuous quantitative variables? Generally, if a class variable exerts strong influence on some domain of observable events, then these events are discontinuously distributed in the multidimensional hyperspace that they define. To the extent that unusual densification (or, in extreme cases, multimodality) can be detected, there exists empirical evidence consistent with a class model.

Unfortunately, however, precise mathematical criteria for determining whether a class 
variable exists cannot be specified without arbitrariness. Class variables simply do not make themselves known in phenotypic hyperspaces in distinct mathematical forms. Rather, they are manifested in varying degrees of discontinuity. Thus, setting a minimum degree of densification to be regarded as evidence of a class variable is necessarily arbitrary. Moreover, continuous, quantitative variables may manifest the same mathematical forms as class variables under certain conditions of sampling and measurement (see Meehl \& Golden, 1982, for examples). ${ }^{\prime}$

In light of these considerations, empirical evidence beyond observed discontinuity is required for a variable to be construed as a natural class variable. Hempel (1965) asserted that class concepts must be given systematic import-that is, demonstrated to fulfill an explanatory or predictive function-to be construed as natural classifications that "carve nature at its joints" (pp. 146-147). For our purposes, we suggest that a construct conjectured to be a class variable be embedded in a network of empirically supported relations that indicate that the construct does represent a class variable. The empirical support should include a complete program designed to establish construct validity of a classification scheme purported to measure the class variable through the same means that a continuous quantitative variable is validated-in terms of the consistency between theoretically derived and empirically observed relations of test behavior with nontest behavior (Cronbach \& Meehl, 1955).

Thus, our efforts to test a class model of self-monitoring propensities involved a twostage process. First, we examined a set of events within the domain of events relevant to self-monitoring-verbal responses to items appearing on the Self-Monitoring Scale-for discontinuities consistent with a class model. Second, we developed a classification scheme based on the observed discontinuities and examined the relation between the classifcation scheme and nontest behavior relevant to self-monitoring. We refer to these two features of our test of the class model as, respectively, the structural component and the external component of the class model (cf. Loevinger, 1957).
The Structural Component of the Class Model: The Strategy of Taxometric Analysis

Over the past two decades, Paul Meehl and his colleagues (e.g., Golden, 1982; Golden \& Meehl, 1979; Meehl, 1965, 1968, 1973; Meehl \& Golden, 1982) have developed a number of taxometric models designed to detect latent class structures in sets of relevant empirical observations. These methods can be applied when the state of knowledge allows one to conjecture the existence of a dichotomous class variable and to supply a list of indicators believed to discriminate (admittedly only imperfectly) between the two classes. These models thus were well suited to our present task. We had conjectured the existence of a latent class variable, and there clearly does exist a set of indicators believed to discriminate between the two classes, namely the items of the Self-Monitoring Scale (Snyder, 1974).

\section{Maximum Covariance Analysis}

These methods are based on a maximum covariance model (Meehl, 1965, 1968, 1973; Meehl \& Golden, 1982). One starts with a substantive theory involving a conjectured dichotomous taxonomy and a set of indicators purported to discriminate between the classes. It is tentatively assumed that the indicators are more or less independent of one another within each class of individuals. That is, the indicators ideally intercorrelate in a sample including individuals from both classes only because the indicators discriminate between classes. (This assumption is only tentative because it can be verified later in the proce-

\footnotetext{
${ }^{1}$ Given that we have conjectured that self-monitoring is a dichotomous class variable, should we not expect the distribution of self-monitoring scores to be bimodal? Although some theorists have defined class variables explicitly in terms of multimodality (e.g., Cattell, 1979), class variables viewed as latent entities do not necessarily, and perhaps only rarely, make themselves known through bimodality of an indicator scale. In fact, it is a simple exercise to demonstrate that bimodality occurs only when there exists very little overlap between latent classes on an indicator scale (e.g., Murphy, 1964), a situation one cannot readily expect when self-report items are used as indicators (Meehl \& Golden, 1982). Clearly, then, bimodality is too stiff a criterion for purposes of evaluating the class model.
} 
dure.) If these conjectures and assumptions are correct, then the identified indicators behave in relation to one another in predictable ways that are not predictable from a dimensional model. The series of procedures we applied were designed to assess the consistency between conjectured and observed behavior of the indicators. We make no claim that any single procedure is sufficient, in itself, to identify a class structure underlying the set of indicators. Rather, it is observed consistency across the entire series of procedures that provides evidence for the latent class structure.

In extensive Monte Carlo runs, as well as in a real empirical trial, the maximum covariance model has been shown to effectively detect real latent class structures, and not to spuriously detect class structures when none exists (Golden \& Meehl, 1973, 1979; Meehl, 1978). Nevertheless, as a precaution against spuriously inferring the existence of real empirical classes in the self-monitoring domain, we instituted two series of control analysesfirst, a real variable control series and, second, a Monte Carlo control series. Each series of control analyses (to be discussed in fuller detail) was designed to demonstrate that, in addition to being able to detect a real latent class structure when they should detect a real latent class structure, the taxometric methods fail to detect a latent class structure when they should fail to detect such a structure.

We first selected, on both empirical and intuitive grounds, eight self-monitoring items (Table 1) that would meet the assumptions and requirements of the taxometric procedures. On empirical grounds, we considered only items that correlated relatively highly with the rest of the measure, reasoning that if the items are influenced by a latent selfmonitoring class variable, then any individual item that discriminates between the classes should correlate with the entire measure. On intuitive grounds, we attempted to not include two items that would correlate substantially within the two conjectured classes. The general rule of thumb here was to not nominate two items of extremely similar manifest content. Thus, the items "I have never been good at games like charades or improvisational acting" and "I find it hard to imitate the
Table 1

Eight Self-Monitoring Items Selected for

Taxometric Analyses

\begin{tabular}{ccc}
$\begin{array}{c}\text { Item } \\
\text { no. }\end{array}$ & Keying & \multicolumn{1}{c}{ Item } \\
\hline 4 & F & $\begin{array}{c}\text { I can only argue for ideas } \\
\text { which I already believe. } \\
\text { I guess I put on a show to } \\
\text { impress or entertain } \\
\text { people. }\end{array}$ \\
\hline I would probably make a \\
good actor.
\end{tabular}

Keying indicates high self-monitoring direction of scoring.

behavior of other people" were not included, despite relatively high item-total correlations, because a similar item with a higher correlation, "I would probably make a good actor," was included. Seven of the items included on these grounds fell into the 9 best items (out of the original 25) in terms of high itemtotal correlation. (The two items above were the exceptions.) The eighth item included, "I can only argue for ideas which I already believe," had content quite different from the other items included. As well, it had a fairly high item-total correlation. ${ }^{2}$

\footnotetext{
${ }^{2}$ The reader may ask why we chose eight items. As our discussion of the method reveals, either seven or eight items is probably the minimum number of items that the method allows. And, given redundancies in content within the set of items on the measure highly correlating with the total scale score, we would have risked including too many item pairs with substantial within-class correlations had we included more than eight items. Thus, although the choice of eight items was necessarily somewhat arbitrary, the choice was also reasoned.
} 
In the first phase of the taxometric procedures, we selected two items, which we call $i$ and $j$, from the pool of the eight conjectured items. We constructed a 7-point scale from the remaining six items (all keyed in the high self-monitoring direction). Out of a sample of 1,918 University of Minnesota students who had completed the Self-Monitoring Scale as part of larger questionnaire sessions between winter quarter, 1979, and fall quarter, 1981, we formed seven subsamples, each comprising the set of individuals who obtained a given score on the 7-point scale. ${ }^{3}$ (Thus, one subsample consisted of all those individuals who obtained a zero; a second sample, all who obtained a one, etc.) For each sample, we computed the covariance between $i$ and $j$ (with $i$ and $j$ also keyed in the high self-monitoring direction). If a class variable underlies the responses to the items as conjectured, if the classes are of not too unequal size, and if auxiliary assumptions to be verified later hold, then the seven sample covariances between $i$ and $j$ plotted as a function of the values on the 7-point scale associated with the samples should be peaked, maximal toward the middle values and nearer to zero toward the extremes. If no class variable exists, no reason exists to expect a peaked covariance curve. See the Appendix for a complete explication of this prediction.

We need not restrict ourselves to the results of a single covariance curve. We could-and we did-repeat this procedure using different pairs of indicators associated with their appropriate six-item scales. Thus, given all possible pairs of the eight items, using with each pair the scale composed of the remaining six items, we made 28 sets of observations that were largely independent and, to reduce sampling variation and the effects of small assumption departures, we aggregated across these 28 sets of observations. To further reduce sampling variation and the effects of assumption departures, we also (as recommended by Meehl, 1973) smoothed the average of the covariances as a function of the 7-point scale by means of methods described by Tukey (1977; in particular, Tukey's "3RH, twice" method of smoothing). All further analyses, however, were performed on both the smoothed and raw, unsmoothed covariance curves. The examination of these 28 covariance curves considered as a whole, then, constituted the first step of the taxometric analyses.

Figure 1 shows the average covariance between two items (across the 28 pairs) as a function of the score on the corresponding 7-point scale that emerged from our analyses. This covariance curve averaged across all 28 item pairs appears consistent with the one expected if a class model is the appropriate model for self-monitoring propensities. The function is peaked toward the middle (values $3 \& 4$ ) and relatively drooped toward the extremes. $^{4}$

\section{Estimates of Base Rates}

Observation of covariance curves across the 28 pairs consistent with a dichotomous class model can only be taken as provisional support for the class model. For us to justifiably conclude that a class model is appropriate, we must observe additional evidence that exhibits consistency with the model. If a latent dichotomous class variable does underlie the responses to the indicators, then a specific parameter-the proportion of the population belonging to one class and the proportion belonging to the other classdefines the distribution of the class variable.

Naturally, any set of mathematical formulae derived from the class model and used

\footnotetext{
${ }^{3}$ Unless otherwise noted, all analyses reported in this article are based on this same sample of 1,918 individuals. We examined the distribution of self-monitoring scores for this sample. Although the distribution was not bimodal, it was not normal either. Compared to a normal curve, it bulged on its sides and was short near its mode, consistent with what we would expect if there existed two partly overlapping latent distributions. More formally, when we assessed the fit of the kurtosis of the distribution with that of a normal curve, it was clearly different; Fisher's (1946) $g_{2}=-.36, z=-3.21, p<.005$.

4 Because a different 7-point scale was constructed for each pair of items, the 28 covariances averaged to calculate each data point in Figure 1 are not calculated from precisely the same groups of individuals. Any given sixitem scale, however, shares at least four items with any other scale, and thus, if two classes exist, the groups of individuals upon which the 28 covariances are based should be similar in their expected relative composition of individuals from the two latent classes. Thus, the shapes of the covariance curves should be similar for each of the 28 item pairs. For ease of presentation, we have averaged the covariances as if they were calculated from the same groups.
} 


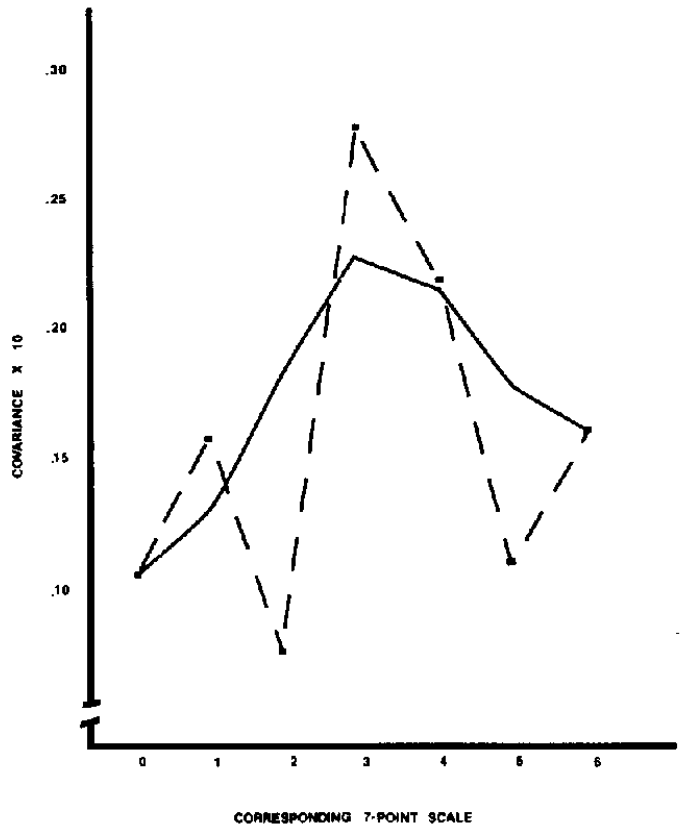

Figure 1. Covariance between self-monitoring items averaged across all 28 item pairs as a function of corresponding 7-point scales. (Solid line represents smoothed function; broken line represents raw function.)

to estimate base rates in our sample (that is, proportions of high and low self-monitoring individuals) should give approximately the same estimates if two real classes do exist, given that these base rates are fixed. If real classes do not exist, making the class model inappropriate, and if different sets of mathematical formulae used to estimate the "base rates" (which themselves, in such an instance, would not exist) are not derivable from one another or from an interpretive text other than the class model, then consistency of the output of the different mathematical formulae must be considered coincidence. Stated simply, if different methods to estimate the base rates fail to provide consistent estimates, either the class model is inappropriate or some auxiliary assumptions of the methods have not been satisfied. Conversely, it is unlikely that different, nonredundant methods would provide consistent estimates if actual base rates corresponding to real empirical classes did not exist. Thus, consistent base rate estimates ought to increase faith in the class model.
One method (Method 1) of estimating the base rates operates on the covariance curve yielded by the first stage of the taxometric analysis (see Meehl, 1973; Meehl \& Golden, 1982). We applied this method to both the unsmoothed and smoothed covariance curves to obtain two base rate estimates. We also applied the method to the covariance values averaged across all possible pairs involving a given item for each item to obtain eight additional estimates. These base rate estimates, although not fully redundant, are also not totally independent. Therefore, we applied two additional methods to our sample to obtain two estimates that are largely independent of those yielded by the maximum covariance method. The mathematical procedures of these two additional methods (Methods 2 and 3) are described by Golden \& Meehl (1979) and Golden (1982), respectively.

The three methods did yield remarkably consistent estimates of the base rates in our sample. Specifically, Method 1, when applied to both the smoothed and the unsmoothed covariance curves, yielded an estimated base rate of .42 for the high self-monitoring class. In addition, the eight estimates corresponding to each of the indicators were consistent and averaged .40. Furthermore, and most important, Methods 2 and 3 provided estimates highly consistent with those provided by Method 1: estimates of .43 and .42 , respectively. Table 2 provides a tabulation of all base rate estimates.

\section{A Real Variable Control: The Case of Impulsivity}

The peaked covariance curves and the consistency of the base rate estimates are both consistent with a class variable underlying the self-monitoring indicators. We must admit that with a methodology examining complex multivariate relations, some unexamined formal aspects of the model may make these results not fully unexpected even under a dimensional model.

Could it be, for instance, that despite the fact that the base rate estimate methods are not derivable from one another, their results are actually highly constrained to be similar under a dimensional model? And, is it also possible that despite the fact that peaked 
Table 2

Estimates of Class Base Rates

\begin{tabular}{ccccc}
\hline & & \multicolumn{3}{c}{ Method } \\
\cline { 2 - 5 } Item no. & 1 & 2 & 3 \\
\hline & 4 & .40 & .43 & .43 \\
6 & .42 & .43 & .43 \\
& 8 & .42 & .40 & .39 \\
12 & .39 & .39 & .40 \\
& 13 & .36 & .40 & .39 \\
& 18 & .44 & .42 & .41 \\
& 21 & .41 & .49 & .49 \\
& 22 & .38 & .45 & .44 \\
Average & & .40 & .43 & .42 \\
Averaged curve & .42 & - & - \\
Averaged curve smoothed & .42 & - & - \\
\hline
\end{tabular}

- Values given are estimates of base rate for high self-monitoring class. Estimates for low self-monitoring class can be calculated by subtracting values from 1 .

covariance curves are not expected under general dimensional models, they are, in our particular instance, the result of the specific configuration of difficulty levels of, and intercorrelations between, our indicators? More generally, is it possible that when the methods should fail to detect a latent class structure, they do not fail to detect a latent class structure?

These possibilities are legitimate concerns and should be addressed. Fortunately, they need not be addressed solely on formal grounds. They may be addressed empirically. Specifically, we performed two series of control analyses. The first series applied the taxometric methodology on real data tapping another variable presumed to be dimensional. The question we asked here was, Can the taxometric analyses fail to detect a class structure underlying a set of indicators when the latent variable is presumably dimensional and, thus, when the methods should fail to detect a class structure?

For these analyses, we chose the variable of impulsivity, a variable we had no reason to suspect to be taxonic. As specific indicators, we chose items that load on the impulsivity factor of the Eysenck Personality Inventory (Eysenck \& Eysenck, 1968). We selected these items to match, as closely as possible, the self-monitoring items in terms of (a) average intercorrelation between items; for self-mon- itoring, $r=.16$; for impulsivity, $r=.16$; (b) range of intercorrelations between items; for self-monitoring, $r$ s range from .01 to .41 ; for impulsivity, $r$ range from .03 to .47 ; and (c) range of item difficulties; for self-monitoring, difficulties range from .29 to .72 ; for impulsivity, difficulties range from .32 to $.75 .^{5}$

We administered the items to 934 University of Minnesota undergraduates in psychology between spring quarter, 1979 , and winter quarter, 1984, and applied the taxometric maximum covariance procedures. Figure 2 shows the covariance curve averaged across all possible $28 i j$ pairs. Clearly, in contrast to the smoothed self-monitoring covariance curve, this smoothed function demonstrates no peakedness.

Is it the case that peakedness would emerge if we examined only the covariances between those items deemed, by an independent method, to best discriminate between classes? Method 2 of estimating the latent base rates also yields estimates of item validities (see Golden \& Meehl, 1979). On the basis of these estimates, we identified the half (4) of the items that best discriminates between possible latent classes. We also went back to the self-monitoring data and similarly identified the four items that best discriminate between conjectured self-monitoring classes. We then calculated and averaged the covariance curves of $i j$ pairs involving only the identified items. As Figure 3 clearly illustrates, the peak of the covariance curve involving the best self-monitoring items is, as would be predicted under a class model, markedly accentuated. In contrast, the covariance curve involving impulsivity items is, once again, not peaked.

Furthermore, the base rate estimates of possible latent classes underlying impulsivity were not consistent. Thus, for instance, the estimates yielded by Method 1 applied to the

\footnotetext{
5 These eight items were "Are you usually carefree?" (keyed yes, Y), "Do you generally do and say things quickly without stopping to think?" (Y), "Do you often do things on the spur of the moment?" (Y), "Can you usually let yourself go and enjoy yourself a lot at a lively party?" $(Y)$, "Do you hate being with a crowd who play jokes on one another?" $(N)$, "Do you like doing things in which you have to act quickly?" (Y), "Can you easily get some life into a rather dull party?" (Y), and "Do you like playing pranks on others?" $(Y)$.
} 


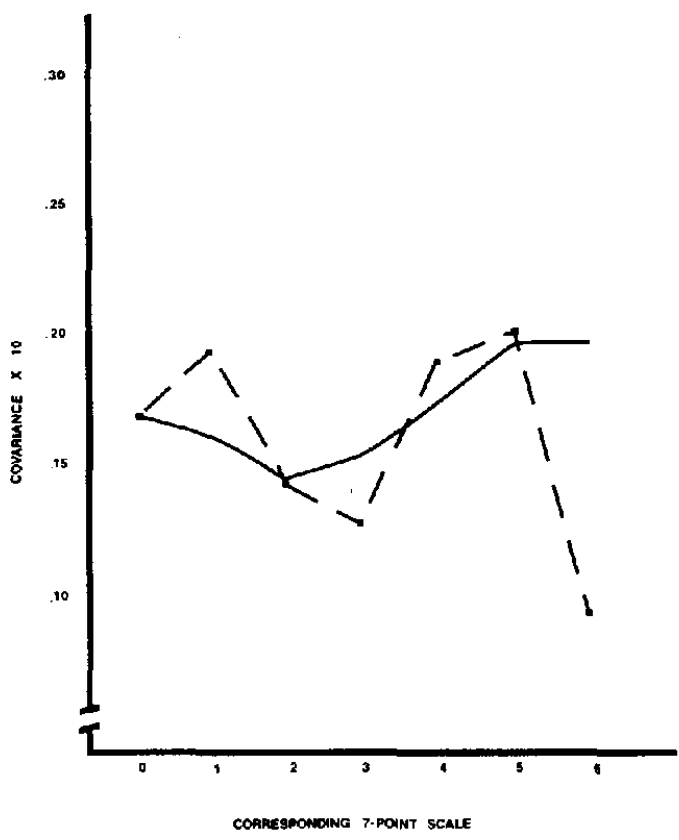

Figure 2. Covariance between impulsivity items averaged across all 28 item pairs as a function of corresponding 7-point scales. (Solid line represents smoothed function; broken line represents raw function.)

unsmoothed and smoothed covariance curves were .36 and .34 , respectively, whereas Method 1 applied to covariance curves associated with individual items gave estimates averaging .63. Methods 2 and 3 yielded estimates of .53 and .49 , respectively, and were thus inconsistent with each of the estimates given by Method 1 .

In sum, the taxometric methods applied to indicators of impulsivity clearly did not indicate the existence of a latent class structure. Thus, when the methods should have failed to detect a latent class structure, they did fail to detect a latent class structure. These findings thereby increase our faith that the taxometric methods appropriately detected a latent class structure underlying selfmonitoring indicators.

\section{A Monte Carlo Simulation}

We also implemented a second series of control analyses. Perhaps support for the latent class structure is attributable to the precise configuration of self-monitoring item difficulties and interitem correlations such that the response tendencies underlying the items possess a multivariate normal distribution. Assuming a multivariate normal distribution of the latent response tendencies to the eight items (as is conventional in formal latent trait approaches; e.g., Lord \& Novick, 1968), we estimated the tetrachoric correlations between all possible pairs of response tendencies. When factor analyzed, with unities in the diagonals, the correlations yielded eight principal components. To create a Monte Carlo sample that, if the actual distribution of response tendencies is multivariate normal, should be a facsimile of the actual sample, we generated 10,000 cases, each assigned eight normally distributed orthogonal principal component values. We then calculated values of response tendencies for a given item for each case by summing the products of principal component values and factor loadings for that item. By then dichotomizing each item response tendency at its difficulty level within the real data sample, we created

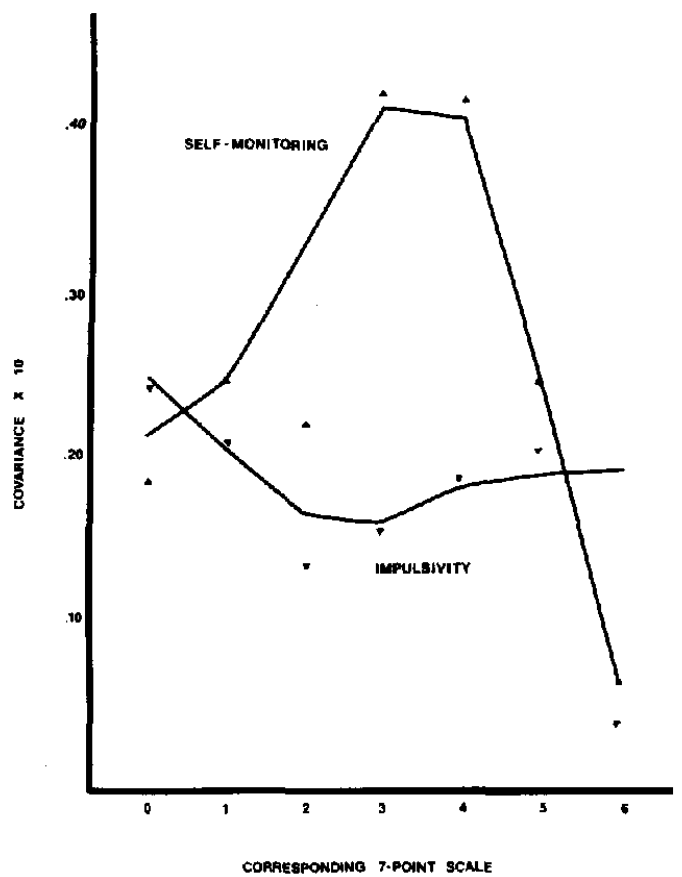

Figure 3. Covariance between best self-monitoring items and best impulsivity items as a function of corresponding 7-point scales. (Solid lines represent smoothed functions. Upright triangles represent raw self-monitoring data points. Inverted triangles represent raw impulsivity data points.) 


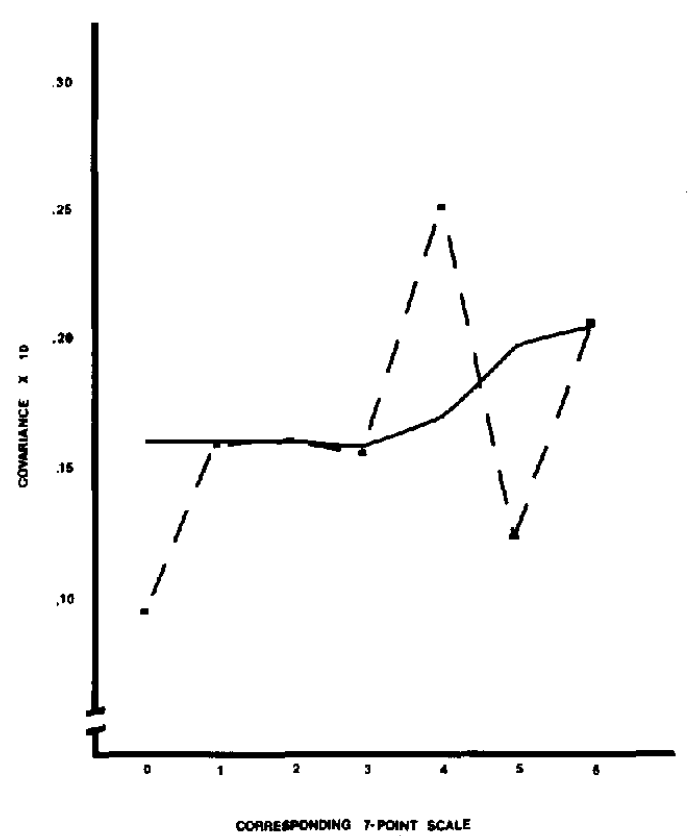

Figure 4. Covariance between simulation items averaged across all 28 item pairs as a function of corresponding 7-point scales. (Solid line represents smoothed function; broken line represents raw function.)

a sample with item characteristics (intercorrelations, difficulty levels) nearly identical to those of our real sample, but generated by a latent dimensional model.

If the alternative explanation is appropriate, then the taxometric methods should yield the same results when applied to the Monte Carlo sample and to the real data. In fact, the results were markedly different. The covariance curve averaged across the 28 item pairs of the Monte Carlo sample was flattened, relative to the covariance curve averaged across the 28 item pairs of the real data set. Figure 4 illustrates this covariance curve. Furthermore, base rate estimates were no longer consistent. Method 1 yielded estimates for the base rate of the high self-monitoring class when applied to the unsmoothed and smoothed covariance curves of .33 and .29 , respectively. The estimates provided by Methods 2 and 3 were .42 and .45 , respectively.

The results of the series of analyses applied to the Monte Carlo data, then, indicate that the support for the existence of a latent class variable underlying self-monitoring phenomena is not attributable to the specific item difficulties and intercorrelations of the selfmonitoring indicators. ${ }^{6}$ Once again, when the taxometric methods should have failed to detect a latent class structure, they actually did fail to detect a latent class structure. Let us now return to an examination of further evidence relevant to evaluating the class model conjectured to appropriately account for the latent structure of self-monitoring.

\section{Additional Considerations: Factor Analysis and the Class Model}

The taxometric analyses have provided considerable corroboration for the conjecture that the latent variable underlying responses to the self-monitoring measure is a class variable. We observed systematic variance between pairs of items consistent with the class model, and we observed a consistent set of base rate estimates, as entailed by the class model. Moreover, two series of control analyses did not support alternative explanations for these findings.

If a class variable is, as we have claimed, a major source of covariation in the responses to items on the self-monitoring measure, then we should be able to find this self-monitoring class variable as a factor emerging from a factor analysis of the Self-Monitoring Scale. Furthermore, if the assumption of local in-

\footnotetext{
${ }^{6}$ In constructing the Monte Carlo simulation sample, we assumed that the latent response tendencies possessed a multivariate normal distribution. Technically, then, this set of control analyses only addresses those alternative dimensional models for which response tendencies are distributed, if not normally, at least quasi-normally. Therefore, the Monte Carlo analyses have unknown relevance for other alternative models in which latent response tendencies are not distributed normally, for instance, those for which response tendencies have markedly skewed distributions. Although this may appear to be a possible limitation of the Monte Carlo control analyses, we should note that our other set of control analyses, the real variable control analyses involving impulsivity, is not hampered by such a limitation. For that set of control analyses, the distribution of response tendencies possessed their naturally occurring form, whether normal, quasi-normal, or not normal at all. Furthermore, there is no a priori basis for believing that, whereas alternative models employing normally distributed response tendencies underlying our item characteristics produced inconsistent base rate estimates, other alternative models employing response tendencies not normally distributed would produce consistent base rate estimates, as the real self-monitoring responses actually do.
} 
dependence holds reasonably, such that within latent classes items do not highly intercorrelate relative to their correlation in the mixed sample, then the class variable should emerge as a general factor accounting for a relatively large amount of the common variance shared across items. In other words, the class variable should emerge as the first unrotated factor extracted in a principal components analysis (Rummel, 1970).

The unrotated factor solution. To identify this first unrotated factor, we performed a principal axes factor analysis with iteration to determine communalities (Statistical Package for the Social Sciences, SPSS, subroutine PA-2) on the self-monitoring items responded to by the 1,918 participants in the sample we used for the taxometric analyses. Based on the results of a scree test (Cattell, 1966), we extracted three factors. If the first unrotated factor does, as conjectured, closely correspond to the self-monitoring class variable, then the factor loading for a given item should be a good estimate of that particular item's correlation with the class variable (i.e., its ability to predict individuals' membership in the class of high self-monitoring individuals or in the class of low self-monitoring individuals).

Using Bayes's theorem and information obtained in the taxometric analyses of the self-monitoring items (specifically the estimated crude validities of the items) we could calculate, for each individual, on the basis of his or her responses to the eight selected selfmonitoring items, the probability of belonging to the class of high self-monitoring individuals and, alternatively, the probability of belonging to the class of low self-monitoring individuals (see Golden \& Meehl, 1979). Individuals with a probability of greater than .5 of belonging to the class of high self-monitoring individuals were assigned to the high self-monitoring class. Those with a probability of greater than .5 of belonging to the low self-monitoring class were assigned to the low self-monitoring class. For $63 \%$ of our sample, we could be at least $90 \%$ confident of their classification. Averaging across all individuals, we estimate that $89 \%$ of classifications were correct ones. Given this taxometric classification scheme, we could estimate each item's correlation with the class variable by calculating the phi
Table 3

Correlations Between Self-Monitoring Items and Self-Monitoring Class Variable Estimated by Taxometric Procedures and Factor Analysis

\begin{tabular}{|c|c|c|c|}
\hline \multirow[b]{2}{*}{$\begin{array}{c}\text { Item } \\
\text { no. }\end{array}$} & \multicolumn{2}{|c|}{ Estimates } & \multirow[b]{2}{*}{$d^{\mathrm{a}}$} \\
\hline & $\begin{array}{l}\text { Taxometric } \\
\text { procedures }\end{array}$ & $\begin{array}{l}\text { Factor } \\
\text { analytic }\end{array}$ & \\
\hline 1 & .25 & .39 & .14 \\
\hline 2 & .02 & .04 & .02 \\
\hline 3 & .14 & .20 & .06 \\
\hline 4 & .24 & .24 & .00 \\
\hline 5 & .28 & .39 & .11 \\
\hline 6 & .53 & .48 & .05 \\
\hline 7 & .06 & .08 & .02 \\
\hline 8 & .63 & .59 & .04 \\
\hline 9 & -.01 & -.02 & .01 \\
\hline 10 & .05 & .02 & .03 \\
\hline 11 & .06 & .11 & .05 \\
\hline 12 & .48 & .45 & .03 \\
\hline 13 & .25 & .25 & .00 \\
\hline 14 & .14 & .28 & .14 \\
\hline 15 & .04 & .06 & .02 \\
\hline 16 & .13 & .22 & .09 \\
\hline 17 & .13 & .17 & .04 \\
\hline 18 & .48 & .41 & .07 \\
\hline 19 & .07 & .09 & .02 \\
\hline 20 & .34 & .49 & .15 \\
\hline 21 & .30 & .34 & .04 \\
\hline 22 & .41 & .45 & .04 \\
\hline 23 & .17 & .31 & .14 \\
\hline 24 & .20 & .30 & .10 \\
\hline 25 & .11 & .18 & .07 \\
\hline
\end{tabular}

"Absolute value.

coefficient between the item and the dichotomous categorization of individuals into high self-monitoring and low self-monitoring classes.

In Table 3 we present the factor loadings of the first unrotated factor and the phi coefficients derived from the taxometric analyses. As can be seen, the orderings of the coefficients within the two sets were remarkably similar to one another. Indeed, a rankorder correlation between the two sets of coefficients approached unity, $r=.97 .^{7}$

\footnotetext{
${ }^{7}$ The taxometric classification scheme allowed us to assess the extent to which the auxiliary assumption of independence of indicators within classes was violated. The items were largely independent within the subsamples of high and low self-monitoring individuals, mean interitem correlations being -.03 and -.02 , respectively. Within the subsample of probable high self-monitoring individuals, correlations ranged from -.16 to .21 , with $75 \%$ between -.1 and .1 . Within the subsample of probable low self-monitoring individuals, correlations ranged from -.14 to .20 , with $86 \%$ between -.1 and .1 .
} 
Thus, although we cannot claim that the first unrotated factor corresponds precisely to the self-monitoring class variable, it does appear that the self-monitoring class variable is expressed as the first unrotated factor. Of course, given the means by which we selected the eight items for the taxometric analyses (on the basis of high item-total correlations), one cannot be too surprised that these two sets of coefficients do correlate strongly. We thus do not suggest that this analysis constitutes independent evidence for the class model. ${ }^{8}$ Nevertheless, an understanding that the latent class variable, should it exist, is reflected as the first unrotated factor will lead us to nonredundant assessments of the class model on the basis of analyses involving the rotated factors.

The rotated factor solution. Previous reports of factor analyses of the Self-Monitoring Scale (e.g., Briggs, Cheek, \& Buss, 1980; Furnham \& Capon, 1983; Gabrenya \& Arkin, 1980; Sparacino, Ronchi, Bagley, Flesch, \& Kuhn, 1983; Tobey \& Tunnell, 1981) have not discussed the possibility that a "true" axis corresponding to a "real" influence is the general first unrotated factor. Instead, these reports have only offered discussions of the factor structure resulting from rotation in accordance with principles of simple structure. Simple structure yields a location of the axes (factors) that makes for easy description of the factors, and thus lends interpretability to the factor structure (see Thurstone, 1947), but rotation to simple structure categorically does not ensure identification of the "real" variables underlying the responses. That is, there is no indisputable justification for believing that a rotated factor structure identifies the "real" underlying sources of variation (e.g., Eysenck, 1950; Guilford \& Zimmerman, 1963; Overall, 1964).

Nevertheless, the rotated factor structure is not at all uninformative. An oblique rotation (SPSS direct oblique criterion of simple structure) of the factors extracted in our sample yielded three factors similar to the three factors reported by Briggs et al. (1980). Because Briggs et al.'s analyses and reportings of factor loadings are already available in the literature and because their factor structure has been employed by other investigators (e.g., Cheek, 1982; Riggio \& Friedman, 1982;
Siegman \& Reynolds, 1983; Sypher \& Sypher, 1983), we employed their recommended factor scales for all analyses involving the factors.

These three factors are all positively correlated with the first unrotated factor. From our perspective, then, these factors define three content areas that discriminate the high self-monitoring class from the low self-monitoring class. We describe the three content domains captured by these factors in order of their importance to the self-monitoring class variable, as reflected by their correlations with the first unrotated factor:

1. An expressive self-control content domain. Items that load highly on this factor concern ability to act, ability to play games that require expressive control, and ability to conceal motives through expressive control (e.g., "I can look anyone in the eye and tell a lie with a straight face"). Briggs et al. (1980)

\footnotetext{
${ }^{8}$ This situation notwithstanding, it may be possible to provide some such independent evidence. Maxwell (1971) noted that scores on a factor discriminating between two latent classes may possess a bimodal distribution, providing that several conditions exist, including the condition that the class means on the variables loading on this factor are substantially disparate. As Grove (1983) discussed, this assessment is probably not very powerful for purposes of testing a latent class model. Nevertheless, we examined the distribution of factor scores on the first unrotated factor. This distribution did appear to possess two distinct modes: a major mode at .3 standard deviations below the mean and a second mode at .9 standard deviations above the mean. If we assume that the midpoint between these two modes is near the optimal cutting score for dissecting two latent distributions, we estimate base rates of .38 and .62 for the high and low ends, respectively, base rate estimates very similar to the base rate estimates yielded by the taxometric analyses. As we should also expect, the kurtosis of the distribution was substantially platykurtic, Fisher's $g_{2}=-.71$, and significantly different from the kurtosis of a normal distribution, $z=6.31, p<.001$. As a precaution against the possibility that the nature of this distribution is merely a function of the fact that all variables factored are dichotomous, we examined the distribution of the first unrotated factor emerging from an analysis of the responses to the Eysenck Personality Inventory provided by our sample of 934 individuals. This distribution did not possess kurtosis significantly different from a normal distribution, $g_{2}=$ $-.21, z=1.34$, ns. And, the distribution of the first unrotated factor of the Self-Monitoring Scale was significantly more platykurtic than was the distribution of the first unrotated factor of the Eysenck Personality Inventory, $z=2.53, p<.02$. Thus, these analyses of the distribution of the first unrotated factor of the Self-Monitoring Scale may provide some independent evidence for the claim that this factor taps a latent class variable.
} 
have interpreted this factor as acting ability. The estimated correlation between this factor and the class variable is $.61 .^{9}$

2. A social stage presence content domain. Items that load highly on this factor concern not feeling awkward in public situations, being the center of attention in groups, and being a storyteller and jokester (e.g., "In a group of people I am rarely the center of attention"). Briggs et al. (1980) have interpreted this factor as extraversion. The estimated correlation between this factor and the class variable is .50 .

3. An other-directed self-presentation content domain. Items that load highly on this factor concern attempts to act in social situations by displaying what others would like or expect one to display (e.g., "I may deceive people by being friendly when I really dislike them"). Briggs et al. (1980) have interpreted this factor as other-directedness. The estimated correlation between this factor and the class variable is .32 .

We should point out that in each case, we believe that Briggs et al.'s interpretation of the content areas corresponding to the factors is too broad. Thus, for instance, the items that define the social stage presence content area, we believe, do not correspond to sociability or extraversion in general. Rather, as our interpretation connotes, they appear to be concerned with feeling comfortable performing in typical group social situations.

But why do these three factors emerge? If all of the common variance were attributable to the self-monitoring class variable (i.e., if the self-monitoring measure were a "pure test," Lazarsfeld, 1950, with any pair of items correlating only because they both discriminate between the classes), then a factor analysis of the items of the Self-Monitoring Scale would, of course, yield a single factor, that corresponding to the self-monitoring class variable. The items on the Self-Monitoring Scale, however, do not correlate only because they discriminate between self-monitoring classes. Some items having to do with similar content do correlate within classes. These items should load on the same rotated factor. Items that load on different factors, we suggest, should not correlate within classes.

In fact, the average interitem correlations for items loading on separate factors are -.03 and -.01 within the classes of high and low self-monitoring individuals. However, the average interitem correlations for items loading on the same factor are .11 and .12 within the classes of high and low self-monitoring individuals. It follows that each of the three factors yields relatively internally consistent scales within each of the two samples: Within the sample of probable high self-monitoring individuals, $\alpha$ 's $=.45, .58$, and .43 for the three factors of expressive self-control, social stage presence, and other-directed self-presentation, respectively; within the sample of probable low self-monitoring individuals, $\alpha$ 's $=.35, .64$, and .51 , respectively. (Given the small number of items on each subscale, these alphas are, in general, not unrespectable.)

As revealed by their correlations with the self-monitoring class variable, these factors thus serve as fallible indicators of the class variable. And, as revealed by the relatively high internal consistency of the factors within the samples of probable high and low selfmonitoring individuals, these factors correspond to sources of variation in the items that are partly orthogonal to the self-monitoring class variable. Thus, we may speculate that the three rotated factors correspond to three dimensional variables that discriminate between the two classes and yet are, in part, independent of the class variable.

of course, these speculations are all inferred from the taxometric analyses performed on the eight items. Could we assess the conjecture that the three factors are fallible indicators of a latent class variable quasi-independently of these analyses? We could nonredundantly assess this conjecture by applying the taxometric method of maximum covariance, using the three factors as indicator variables. Once again, this method requires indicator variables conjectured to discriminate between the two classes, but not correlate within classes. To ensure more orthogonal sources of variation, we removed the items that loaded on more than one factor from the factor scales on which they loaded more weakly. In addition,

\footnotetext{
${ }^{9}$ To estimate the correlations between the factors and the class variable, we correlated each factor with the dichotomous variable constructed from the eight-item classification scheme.
} 


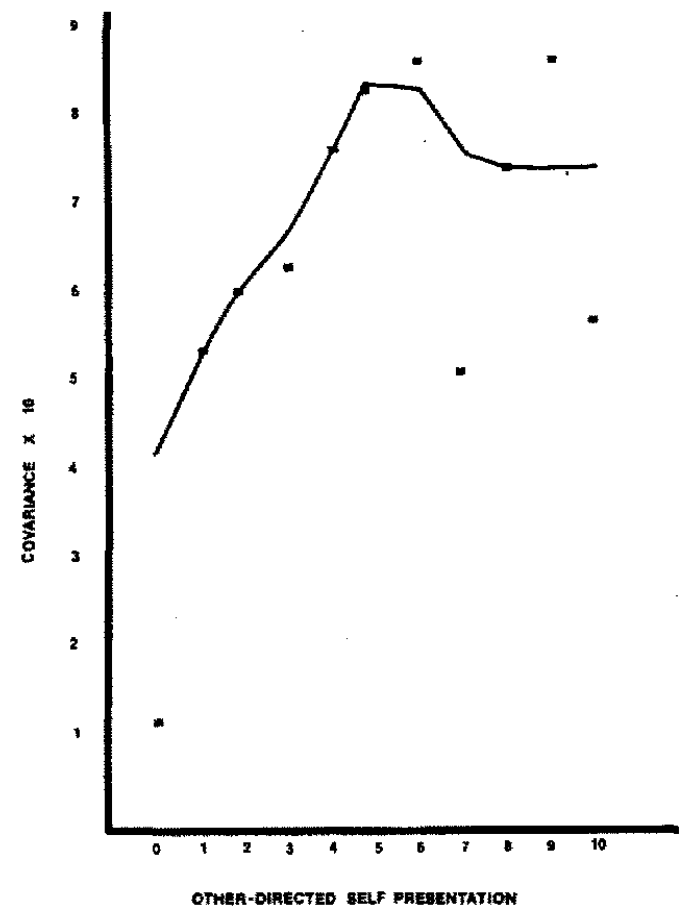

Figure 5. Covariance between expressive self-control and social stage presence factors as a function of otherdirected self-presentation factor. (Solid line represents smoothed function; squares represent raw data points.)

at least one of the variables must be able to be sliced into a number of small intervals. We nominated the other-directed self-presentation factor to be this variable because, containing the largest number of items, it can be sliced into the largest number of intervals.

We separately calculated, for the 11 groups of individuals obtaining each of the possible scores on this factor, the covariance between the other two factors. As predicted, and as is illustrated in Figure 5, a plot of these covariances revealed a curve peaked toward the middle value of the other-directed self-presentation factor scale. The estimated base rate of the high self-monitoring class yielded by a method analogous to Method 1 was .43 , remarkably close to the estimates given by the three quasi-independent methods discussed. The base rate yielded by the same method applied to the Tukey smoothed covariance curve was .44. Finally, as Figure 6 shows, we estimated the latent distributions of the two classes on the other-directed selfpresentation factor to be very similar to the latent distributions on this factor estimated using the taxometric classification scheme derived from the eight-item analysis. These findings thus provide yet more support for the class model. ${ }^{10}$

\section{The External Component of the Class Model: Attributing Systematic Import to the Class Variable}

Clearly, the taxometric analyses indicate that a dichotomous class model is highly consistent with the internal structure of the multinomial relations observed between selfmonitoring items. The plotted covariance curves have the form expected of a dichotomous class model. The estimated relative proportions of the two classes based on three largely nonredundant methods all converge on approximately a $40 / 60$ split of the classes of high and low self-monitoring individuals. Moreover, covariance analyses of factors posited to be independent fallible indicators provided yet additional convergent evidence. Considered together, these findings provide support for the class model that is, indeed, strong.

Nevertheless, these findings are not yet sufficient to conclusively establish that we have identified a class variable possessing the

${ }^{10}$ Readers may wonder about the application of cluster analyses to our data. We also applied a classical cluster analysis to individuals distributed in the three-dimensional space formed by the three obliquely rotated factors. Specifically, we applied Ward's (1963) hierarchical clustering algorithm employing a criterion of minimum increase in within-group sums of squares to 150 individwals on the basis of their factor scores (implemented by a source program derived from a routine of Anderberg, 1973; central memory requirements of this program limited the size of the sample we could cluster to about 150). A number of evaluations indicate that Ward's (1963) clustering algorithm outperforms most, if not all, of the popular algorithms available in recovering known mixtures (e.g., Blashfield, 1976; Kuiper \& Fisher, 1975; Mojena, 1977). This analysis produced two classes with base rates very similar to the base rates our other methods yielded, .39 and .61 . More impressively, the analysis produced classifications of individuals that agreed with $87 \%$ of the classifications produced by the taxometric methods based on eight items. Classical cluster analysis, then too, corroborates our evidence for the appropriateness of a class model. 


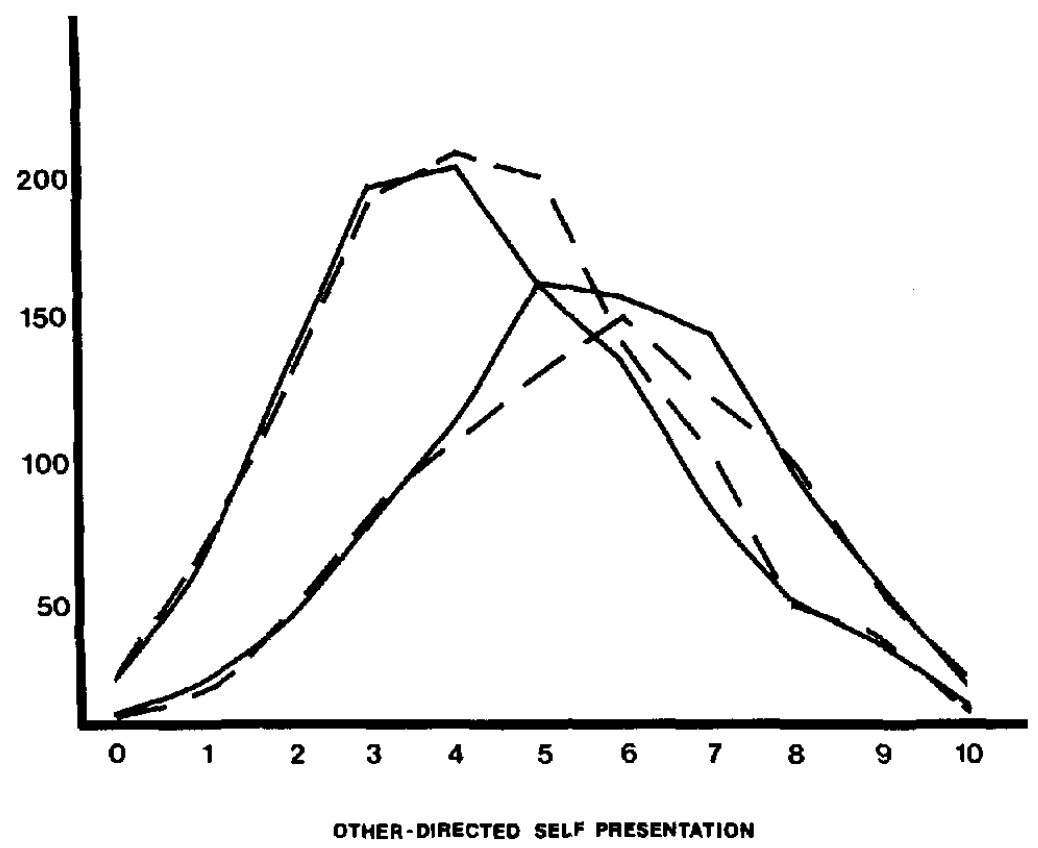

Figure 6. Latent class distributions on other-directed self-presentation factor estimated by maximum covariance method applied to factors (solid lines) and maximum covariance method applied to eight items (broken lines).

sort of systematic import that is psychologically meaningful and conceptually powerful. All of the analyses described thus far have involved only verbal responses to self-report items observed in single test-taking sessions. To establish greater systematic import of the class variable identified by the taxometric analyses, and to further and even more stringently corroborate the class model, we need to examine empirical relations, derived from self-monitoring theory, between responses to the Self-Monitoring Scale and criterion variables observed outside of the test-taking situation. That is, we need to examine empirical relations to criterion variables with which the Self-Monitoring Scale has been linked in empirical investigations. And, we must ask, are these relations consistent with the conjecture that a dichotomous latent class variable accounts not only for relations between responses to different self-monitoring items, but also for relations between responses to self-monitoring items and behavior observed outside of the test-taking situation?

To address this question of the validity of the external component of the class model, we first selected a number of empirical investigations that involved phenomena clearly grounded in theoretical considerations of selfmonitoring processes. These studies cover a relatively wide range of self-monitoring phenomena and processes, involving distinctly different manipulated independent variables and measured dependent measures: (a) Snyder and Cantor (1980), Investigation 2; (b) Snyder and Gangestad (1982), Investigation 1; (c) Snyder and Gangestad (1982), Investigation 2; (d) Snyder and Kendzierski (1982b), Investigation 1; (e) Snyder, Gangestad, and Simpson (1983), Investigation 1; and (f) Snyder, Gangestad, and Simpson (1983), Investigation 2 .

If the class model is indeed appropriate, then, at a minimum, the classification scheme emerging from the taxometric analyses should be able to predict criterion variables in these studies with success comparable to the full 25-item self-monitoring measure. Thus, for each participant in each investigation, we calculated the probability of belonging to the class of high self-monitoring individuals and the probability of belonging to the class of 
low self-monitoring individuals, using the classification scheme based on the eight selected self-monitoring items that emerged from the taxometric analyses. Those with a probability greater than .5 of belonging to the high self-monitoring class were classified as high self-monitoring individuals, and those with a probability greater than .5 of belonging to the low self-monitoring class were classified as low self-monitoring individuals. We then recalculated the statistics ( $F \mathrm{~s}$ or $t \mathrm{~s}$ ) that most directly test the major hypotheses of the studies using, as the measure of self-monitoring, the classification scheme in place of the full 25-item Self-Monitoring Scale.

Table 4 displays the results of these reanalyses. Clearly, the taxometrically derived eightitem classification scheme produced relations almost as strong, as strong, or even stronger than the relations produced by the full SelfMonitoring Scale. It appears, then, that a measure of the class variable detected by the taxometric procedures effectively can stand in for the entire Self-Monitoring Scale and can account successfully for relations between the full self-monitoring measure and behavioral criteria predicted by the theory of selfmonitoring.

But there exist much stronger tests of the class model. Indeed, the results of these tests were some of the most informative with respect to appropriateness of the class model. The analyses discussed thus far demonstrate that the dichotomy produced by the taxometrically derived classification procedure is as related to the external criterion measures as is the dichotomy produced on the SelfMonitoring Scale splits (either at the median or sampling from the ends of the distribution). The most informative question regarding external validation, however, is not addressed by these analyses. Specifically, what happens to the strength of the relations with the external criteria when we take into consideration the information thrown away by dichotomizing?

\begin{tabular}{|c|c|c|c|c|}
\hline \multirow[b]{2}{*}{ Study } & \multirow{2}{*}{$\begin{array}{l}\text { Dichotomized } \\
25 \text {-item self- } \\
\text { monitoring } \\
\text { scale }\end{array}$} & \multirow{2}{*}{$\begin{array}{l}\text { 8-item } \\
\text { taxometric } \\
\text { classification } \\
\text { scheme }\end{array}$} & \multicolumn{2}{|c|}{$\begin{array}{l}\text { Effect size or } \% \text { of variance } \\
\text { accounted for by } \\
\text { classification scheme relative } \\
\text { to full scale }\end{array}$} \\
\hline & & & Actual & $\begin{array}{l}\text { Class model } \\
\text { predictions" }\end{array}$ \\
\hline \multicolumn{5}{|l|}{ Snyder \& Cantor (1980) } \\
\hline$m F(4,53)$ & 2.83 & 2.42 & 1.49 & 1.32 \\
\hline$F(1,56)$ & 8.29 & 4.69 & - & - \\
\hline \multicolumn{5}{|l|}{$\begin{array}{l}\text { Snyder \& Gangestad (1982) } \\
\text { Investigation I }\end{array}$} \\
\hline$F(1,117)$ & 11.49 & 11.23 & 2.70 & 1.62 \\
\hline Investigation 2 & & & & \\
\hline$F(1, \infty)$ & 5.89 & 6.69 & 1.75 & 2.44 \\
\hline$F(1, \infty)$ & 4.24 & 3.83 & - & - \\
\hline \multicolumn{5}{|l|}{ Snyder \& Kenzierski (1982) } \\
\hline $\begin{array}{l}\text { Investigation } 1 \\
F(1, \infty)\end{array}$ & 11 on & 0.43 & 114 & 230 \\
\hline $\begin{array}{c}\text { Snyder, Gangestad, \& Simpson } \\
(1983)\end{array}$ & 11.90 & 9.43 & 1.14 & 2.20 \\
\hline $\begin{array}{l}\text { Investigation } 1 \\
\quad t(28)\end{array}$ & 3.93 & 4.21 & 0.88 & 1.11 \\
\hline Investigation 2 & & & & \\
\hline$t(58)$ & 2.53 & 2.48 & 1.51 & 1.35 \\
\hline Average & - & - & 1.58 & 1.67 \\
\hline
\end{tabular}

- These values reflect corrections for the fallibility of the classification scheme; uncorrected values are not highly dissimilar. 
It is the answer to this question for which the dimensional model and the class model provide clearly different predictions. Consider first the prediction derived from the dimensional model. If the latent variable underlying responses to the self-monitoring indicators is dimensional, and if the relations between the self-monitoring measure and external criteria are essentially linear (as is generally assumed; Jackson, 1971), then the full self-monitoring measure should be more highly correlated with relevant external criteria variables than either the dichotomization of the full selfmonitoring measure or the taxometric classification scheme. On formal grounds, this prediction is straightforward: A biserial correlation is as a rule greater than the point biserial correlation from which it is estimated.

Consider now the prediction derived from the class model. If there is relatively little systematic covariation between the self-monitoring measure and external criteria other than that attributable to a dichotomous class variable, then to best predict external criteria, one should simply want to know to which of the two latent classes individuals belong. Thus, once one knows that an individual belongs to the high self-monitoring class, one should not care whether the person scored 15 or 22 . Similarly, once one knows that an individual belongs to the low self-monitoring class, one should not care whether the person scored 10 or 3 . Indeed, saturating one's predictor variable with this information only introduces error and thus reduces the predictability of criterion variables. Using the taxometric classification scheme based on the responses to the eight items, we can classify individuals with considerable confidence (in fact, with an accuracy rate estimated to be $89 \%$ ). Thus, it follows from the class model that the full self-monitoring measure should be less highly correlated with relevant external criterion variables than is the dichotomization yielded by the taxometric classification scheme.

Each model, then, makes distinctly different predictions. Accordingly, we returned to our six external validation studies and performed new sets of analyses. For each study, we calculated the effect size achieved or percentage of variance accounted for by the taxometric classification scheme, expressed as a proportion of the effect size achieved or per- centage of variance accounted for by the full scale. "If a dimensional model is appropriate, these relative percentages of variance accounted for should be less than 1.00. In contrast, if a class model is appropriate, these relative percentages of variance accounted for should be greater than 1.00 .

The actual relative values are given in Table 4. Generally, they are well above 1.00 , averaging 1.58 . In all but one case, the taxometric classification scheme well outperformed the full scale. These results, then, provide clear additional support for the class model.

The extent of this additional support can be appreciated all the more when one compares the predicted values of these relative proportions with the actually achieved values. If the class variable is the sole variable responsible for the relations between the external critera and the self-monitoring measure, then these relative proportions should be approximately equal to the reciprocal of the proportion of variance in the full scale shared with the class variable. A comparison of these values predicted under the class model and the actual values (see Table 4) reveals that they are very similar. Thus, these analyses not only provide further evidence for the existence of a latent class variable, but also demonstrate that this class variable can, by itself, largely account for the relations between the entire self-monitoring measure and external criterion variables. ${ }^{12}$

\footnotetext{
1" In three studies (Snyder \& Cantor, 1980; Snyder \& Gangestad, 1982, Investigation 1; Snyder \& Kendzierski, 1982), the predicted result involved differences between correlations. In these cases, we calculated the effect sizes of these differences (i.e., $z_{r 1}-z_{r 2}$ ) for both the full scale and the taxometric classification scheme. In the remaining three studies (Snyder \& Gangestad, 1982, Investigation 2; Snyder, Gangestad, \& Simpson, 1983, Investigations 1 and 2 ), the predicted result involved a single correlation. Here, we calculated the percentages of variance of the criterion variable accounted for $\left(r^{2}\right)$ by both the full scale and the taxometric classification scheme.

12 The performance of the rotated factors in predicting the external criterion variables was also assessed. The factors were more weakly related to the nontest behavior than were either the full self-monitoring measure or the eight-item classification scheme. In no study did any of the factors outperform both the 25-item measure and the taxometric classification scheme, despite the fact that the factors have reliabilities comparable to that of the full scale.
} 


\section{Implications of Class Models in Personality}

As we have seen, it is in principle possible that differences between individuals may be expressed either as continuously distributed differences in degree or discretely distributed differences in kind. As we have also seen, this "in principle" situation notwithstanding, it is widely presumed that such differences are most appropriately thought of as continuous dimensions. This pervasive presumption is bolstered by an enduring prejudice against the viability of class models in personality, a prejudice rooted in part in claims that class variables constitute oversimplifications of reality or arbitrary fictions. We have argued that, although these claims may be well taken with respect to phenetically defined class variables, they do not apply to class variables purported to represent genotypic sources of causative influence. Yet, even though genetically explicated class variables ought to be particularly appealing to personality researchers concerned with causal-dispositional constructs that underlie, organize, and structure behavior, we were well aware that the existence of no such class variable (with the exception of biological sex) exerting substantial influence on human social behavior in the general population had been established.

We assert that the existence of one genetically explicated, discrete class variable has been demonstrated and its influence on human social behavior corroborated. The structural relations among individuals' responses to items on the Self-Monitoring Scale are highly consistent with those expected if a latent class variable were a major influence on the responses. Moreover, the class model derived from the self-report items served successfully as a predictor of nontest behavior in diverse studies of self-monitoring. Finally, and equally important, the observations we made are highly inconsistent with a purely dimensional model. Thus, we feel confident that a taxonic structure does underlie selfmonitoring phenomena.

What, then, are the implications of these findings? We propose to begin by examining the empirical findings considered narrowly and ask: What do they tell us about the construct and how it should be measured? Then, we proceed to issues of etiology and development, and inquire: What new perspectives does the class model provide when it comes to conceptualizing development of the class variable and its manifestations? Finally, we plan to address more general issues in personality and pose the question: What are the implications of our inquiry into class models for defining strategies for understanding the nature of personality and the psychology of the individual?

\section{Psychometric Implications of the Class Variable}

Although all but one of the self-monitoring items do correlate in the expected direction with the latent class variable, there does exist substantial variation in the size of these correlations. Among the best discriminating items are "I would probably make a good actor," "I have never been good at games like charades or improvisational acting," "In a group of people I am rarely the center of attention," "At a party 1 let others keep the jokes and stories going," and "I guess I put on a show to impress or entertain others." Items that perform moderately well concern acting like different persons in different situations and attempting to be pleasant to others.

There do exist several items that discriminate rather poorly, if at all, between the classes. Several of these items concern insincere (e.g., "I sometimes appear to others to be experiencing deeper emotions than I actually am") or negative (e.g., "In order to get along and be liked, I tend to be what people expect me to be rather than anything else") behaviors. Whatever the reason may be, the fact that they do not perform well has implications for measuring self-monitoring. Because several items are not good discriminators, we suggest an alternative measure of the self-monitoring class variable. We do not suggest that the measuring instrument be the eight-item classification scheme that emerged from the taxometric analyses, largely because it is not a pragmatic research instrument. To use it, one must know the probabilities of class membership for all 256 eight-item combinations, and the probabilities may not generalize across populations. Instead, we recommend the 18-item measure presented in Table 5. It consists of only those items cor- 
relating at least .15 with the latent class variable, as estimated by first unrotated factor loadings.

This new measure has an internal consistency $(\alpha)$ of .70 , higher than the internal consistency of the original 25 -item measure (.66 in our sample). Moreover, it is more factorially pure than the original measure. Its first unrotated factor accounts for $62 \%$ of the common variance, compared to $51 \%$ accounted for by the first unrotated factor of the 25-item measure. More important, total scores on the new measure are uncorrelated with its second, relatively minor, unrotated factor, $r=.03$. By contrast, total scores on

Table 5

The 18-Item Measure of Self-Monitoring

Item and Key

1. I find it hard to imitate the behavior of other people. (F)

2. At parties and social gatherings, I do not attempt to do or say things that others will like. (F)

3. I can only argue for ideas which I already believe. (F)

4. I can make impromptu speeches even on topics about which I have almost no information. (T)

5. I guess I put on a show to impress or entertain others. (T)

6. I would probably make a good actor. (T)

7. In a group of people 1 am rarely the center of attention. (F)

8. In different situations and with different people, I often act like very different persons. (T)

9. I am not particularly good at making other people like me. (F)

10. I'm not always the person I appear to be. (T)

11. I would not change my opinions (or the way I do things) in order to please someone or win their favor. (F)

12. I have considered being an entertainer. ( $\mathrm{T}$ )

13. I have never been good at gámes like charades or improvisational acting. (F)

14. I have trouble changing my behavior to suit different people and different situations. (F)

15. At a party I let others keep the jokes and stories going. (F)

16. I feel a bit awkward in public and do not show up quite as well as I should. (F)

17. I can look anyone in the eye and tell a lie with a straight face (if for a right end). (T)

18. I may deceive people by being friendly when I really dislike them. (T)

Note. Keying is given by either $\mathrm{T}$ (true) or $\mathrm{F}$ (false) in parentheses following item. High self-monitoring individuals tend to answer in the keyed direction; low self-monitoring individuals tend to answer in the alternative direction. the original measure are mildly correlated with its second unrotated factor, $r=.15$. Finally, the correlation between the new 18item measure and the original 25 -item measure is .93 .

Because the major underlying latent variable measured by this instrument is a class variable, increasing scores represent higher probabilities of belonging to the high selfmonitoring class rather than progressively greater amounts of this latent variable. Thus, appropriate splits should be used to classify people. For our sample, we estimated that the probability of belonging to the high selfmonitoring class was greater than .5 for those with scores of 11 or greater.

\section{Developmental Origins of the Class Variable}

Although these considerations of the relations between self-monitoring items and the underlying classes provide sketches of the behavioral features associated with the two classes, they cannot fully explicate the latent class variable. For, at least as far as we have seen, such phenotypic manifestations are only fallible indicators of the class variable. The explicit nature is likely to be revealed only at some latent underlying level.

Let us consider more closely at what latent underlying level the true explicit nature of the class variable may exist. We need not assume that any underlying homogeneity within the classes necessarily exists at a level describable in existing psychological terms. The homogeneity of the classes of biological sex, for instance, is identifiable with chromosome structure. The differing chromosome structures play a necessary role in a complex causal network, involving extensive social learning processes, that produces the behavioral characteristics associated with the sexes. Because the causal connections are not invariant across individuals, however, the homogeneity at the chromosomal level is not retained through the causal chain to the level of phenotypic behavioral characteristics. The pure homogeneity extends only as far as the chromosomal differences.

It is possible that the homogeneity of the self-monitoring class variable is similarly embedded several levels deep in a causal network producing phenotypic differences. 
As with biological sex, perhaps there exists a dichotomous structure, event, or threshold effect in the biological or psychological past of persons that determines class membership. The resultant class variable then may play a role in a complicated causal network that influences several domains of phenotypic characteristics (e.g., expressive self-control, social stage presence, other-directed self-presentation). As with biological sex, however, the level of the specific etiological factor may be the only level at which homogeneity of the classes exists.

\section{Etiology of the Class Variable}

Aside from brief speculations in an early treatment (Snyder, 1974) and in a recent treatment (Snyder, 1983b) of self-monitoring, the question of development of differences in self-monitoring propensities remains virtually unanswered. In speculating that a specific etiological factor may be responsible for the class structure detectable in adult behavioral manifestations of self-monitoring, we do not suggest that this specific factor directly prom duces, in full, all of these same behavioral manifestations in childhood. More likely, a specific factor (assuming one exists) produces differences in a circumscribed domain of behavior that then, through a process of divergent causality, produces increasingly large differences over time. Divergent causality occurs when initially small differences between individuals become amplified or extended over time, producing larger differences between individuals in similar domains or in additional domains (Langmuir, 1943; London, 1946; Meehl, 1978; cf. Waddington's, 1957, discussion of the epigenetic landscape). With respect to self-monitoring, perhaps initially small differences in restricted domains exist in children, and then snowball into the extensive differences in wide-ranging domains observed in adults.

First, consider candidates for the specific etiology. One such candidate is a biological genetic structure. Although class determination cannot be so simple as to be traceable to a single Mendelian gene, it is possible that it corresponds to a threshold character or an epistatic configuration of alleles at independently segregating sites. A second possibility is that the class variable corresponds to distinct behavioral strategies acquired by children (perhaps at some critical age) in response to parenting styles, peer pressures, sibling relationships, or in a combination of these and other environmental events. Adoption of one of two strategies may be sensitive to a threshold on some specific environmental parameter, such as amount of attention received from caretakers. More specifically, perhaps children who receive little attention from their caretakers adopt a strategy designed to gain the attention and regard of othersa high self-monitoring strategy. Finally, the specific etiology may involve a combination of environmental and genetic factors. Perhaps adoption of one of two strategies is sensitive to a threshold on a specific environmental parameter, but the threshold value varies across individuals and is largely genetically determined.

We do know of one twin study (Dworkin, 1977) that examined genetic influences on self-monitoring. It is interesting that the monozygotic within-pair variance on the SelfMonitoring Scale was similar to the variance on the Self-Monitoring Scale we estimated to exist within each of the two classes. The dizygotic within-pair variance was, by contrast, more than twice as great as monozygotic within-pair variance and similar to the variance we estimated to exist in mixed college or adult populations. These results, then, are consistent with the possibility that the class structure can be largely traced to genetic origins of an epistatic nature.

\section{Domains of Initial Manifestations}

Assuming some specific etiology or threshold effect does determine class membership, across what parameters of psychological functioning are initial differences produced, and what are their behavioral manifestations? Recent research on individual differences in language acquisition and characteristic symbolic styles suggests one intriguing possibility. Nelson (1973, 1981) and, subsequently, others (e.g., Horgan, 1981; Ramer, 1976; Starr, 1974) observed two relatively distinct patterns in the acquisition of language by children at ages 2-3. Some children, referred to as referential, tend to first learn to use language as 
a referential system that allows one to communicate actual happenings in the world. For instance, they develop a large vocabulary of referential nouns. Other children, referred to as expressive, tend to learn early on the social uses of language. They learn that the pattern, structure, and intonation of linguistic expressions are dependent on social context, and they learn that language is a means to obtain attention from others.

Wolf and Gardner (1979) suggested that these differences in language acquisition are associated with differences in general symbolic activities. Thus, expressive children (whom Wolf and Gardner call dramatists) focus on the social structure of events, learning at an early age that different persons on different occasions can play the same role in the same social situation, and that persons can exchange roles in play. Dramatists also like to tell dramatic stories, and they are able to display elaborate forms of imitation.

The behavioral overlap between the referential-expressive distinction in children and the adult manifestations of the latent selfmonitoring class variable is striking. Both expressive children and high self-monitoring adults are relatively sensitive to considerations of social context and are dramatists in their social performances, being sensitive to the attention that dramatic performances gain and skilled at imitating others. In contrast, both referential children and low self-monitoring adults tend to be relatively insensitive to social context, and nondramatic. On the basis of content validity, we have been led to entertain the possibility that the two sets of individual differences are manifestations of the same latent variable expressed at different ages.

\section{Processes of Divergent Causality}

Initial manifestations of the class variable may involve propensities to learn varying features of the social world, later expressed as actual differences in social knowledge. Similarly, initial differences in potential to acquire role-playing skills eventually may be expressed as actual differences in these skills. Moreover, these skill differences eventually may be reflected in behavioral repertoires, which then may be reflected in actual behav- ioral enactments. Through a process of selfperception (Bem, 1972) these differences in behavior may then be reflected in differences in beliefs about one's self and the guiding principles behind one's actions (cf. Snyder \& Campbell, 1982). Thus, substantial divergent causality may occur through normal processes of acquiring knowledge and skills.

There does exist another scenario by which divergent causality could occur. Consider the case of a dichotomous etiological factor that influences individuals' choices of situations such that individuals gravitate toward environments conducive to the behavioral manifestations of the etiological factor. By virtue of spending time in situations that are particularly conducive to their initial behavioral tendencies, individuals develop behavioral repertoires and skills increasingly consistent with their initial tendencies. Over time, then, individuals differing with respect to the etiological factor increasingly differ with respect to behavioral repertoires and skills (for elaboration of this analysis of choosing situations, see Snyder, 1981, 1983a; cf. Plomin, DeFries, \& Loehlin, 1977).

It has, in fact, been demonstrated that individuals high and low in self-monitoring tend to enter into or create situations and to choose friends in ways conducive to the expression of their own behavioral orientations (e.g., Snyder \& Gangestad, 1982; Snyder, Gangestad, \& Simpson, 1983; Snyder \& Simpson, 1984). Certainly children of gradeschool age exercise considerable control over their choices of friends as activity partners. Perhaps children belonging to the high selfmonitoring class are more sensitive to choosing activity partners who are skilled at the particular activity. And, perhaps children belonging to the low self-monitoring class are more sensitive to choosing activity partners who are well liked and similar to the self. As a result of spending time with their friends, then, high self-monitoring childrens' behavioral repertoires may become increasingly diverse, whereas low self-monitoring childrens' behavioral repertoires, in contrast, may become increasingly uniform, thus creating further divergence in the types of interpersonal situations in which high and low self-monitoring children find themselves. In like fashion, other differentiating choices could create 
additional amplified manifestations of the class variable.

We have devoted extended discussion to divergent causality because identification of a class variable with a specific etiology invites an explicit, systematic investigation of divergent causality. Once a specific etiology has been determined, one can classify individuals and, in principle, determine manifestations of the class variable across time by recurrently sampling behaviors and abilities from wide domains over a long course of development. Clearly, then, an understanding of self-monitoring phenomena can substantially benefit from identification of an underlying latent class variable. Understanding the explicit inner nature of self-monitoring will benefit to the extent that the homogeneity of the class variable is identified. Understanding the roots of self-monitoring will benefit to the extent that a specific etiology or threshold effect determining class membership is identified. And, understanding the development of selfmonitoring will benefit to the extent that increased differentiation between the classes over time is identified. Moreover, identification of the class variable not only raises questions whose answers will be informative, but also raises questions that are, in principle, highly researchable. Thus, identification of the class variable can produce a metamorphosis of understanding, resulting in a confluence of assets rarely seen in personology. At the same time that an understanding of self-monitoring gains the elegance and simplicity entailed by a dichotomous class variable, it gains content and precision.

\section{Implications for Understanding the Nature of Personality}

The issues we have raised about self-monitoring as a class variable can be raised about any class variable in personality. Given identification of a class structure, we may ask: Where does the true homogeneity in the class variable lie? Do the classes have a specific etiology? Do they result from a threshold effect? Does the etiological factor initially affect some circumscribed domain of psychological functioning that, through a process of divergent causality, becomes amplified or extended over time? These questions gain special significance-or only become applicablewhen they concern a class variable. They generally are not applicable or are not feasibly researched when the variable of concern is not a class variable.

Two additional questions, which we did not explicitly address with respect to selfmonitoring, may be addressed with respect to other class variables in personality. First, we may ask, if the variable is the result of a threshold function, is the function a "pure" or an "impure" one? If it is not pure or "tight," a few individuals will end up in an intermediate range between the two classes. Thus, the classes will have fuzzy edges. We suspect that the etiological and developmental considerations that are appropriate when one is dealing with fuzzy classes are more similar to those appropriate for pure classes than to those appropriate for normally distributed dimensions. Thus, fuzzy classes have import similar to that of pure classes, provided the classes reveal true divergences in psychological functioning.

There does exist a type of fuzzy classes that does not reveal true divergences. Recognition of this type of classes brings us to a second question: Are the classes environmental mold types (Meehl, 1972; cf. Cattell, 1979)? Environmental mold types exist not because an important psychological parameter discretely differentiates between classes. Rather, they exist because the structure of the environment dictates divergence. Thus, there are the classes of college students and noncollege students, not because of some discrete divergence in internal structure that distinguishes the two classes, but because of the structure of an educational system. Clearly, many of the intriguing issues concerning etiology and development that one can address with respect to class variables reflecting true divergences are not applicable to environmental mold types.

\section{Consideration of Methods of Discovery in Personology}

How does one go about discovering real, causal latent entities and dispositions in personality? This methodological question has been around about as long as has theoretical inquiry into personality, and is one for which 
we do not pretend to have a failsafe answer. The present effort to discover a real causal entity, however, does have implications for answers to this question.

It is probably the case that the most frequently used method to discover real causal influences in personality-whether that goal is explicitly or implicitly stated-is factor analysis (e.g., Cattell, 1978). As a data-reduction tool, of course, factor analysis has many uses, each of which may involve one or more assumptions justifying its use. For use as a means to discover real causal entities or dispositions underlying a collection of overt behaviors, Cattell (1978) offered the following cosmological assumption as justification for interpreting factors rotated to minimize some criterion of simple structure as real causative influences: Given a set of overt behavioral variables having multiple causative influences, any one underlying influence substantially affects only a portion of the overt variables. It is also often assumed that any one overt variable is likely to be influenced substantially by only one real underlying variable.

But how does one know that these assumptions are correct? In particular, how does one know that these assumptions are correct for the specific variables and the specific sample one has selected? Two prominent factor analysts have aptly answered these questions in stating "As a general rule, the simple structure model may serve as the best objective guide to the location of the basic dimensions of human nature. There is little in the way of proof, however, either logical or empirical, that this is true" [italics added] (Guilford \& Zimmerman, 1963, p. 290; see also Eysenck, 1950).

Thus, identification of the real underlying influences through factor analysis and rotation to simple structure depends in part on getting lucky. If-luckily - the particular set of variables of concern are consistent with the assumptions basic to simple structure rotation, then one discovers the real underlying sources of influence through factor analysis and rotation to simple structure. If these circumstances do not hold, however, the real underlying influences are not discovered in the simple structure.

We should note that Cattell (1978) himself has recognized limitations to the assumptions underlying the use of simple structure to identify real sources of influence:

Simple structure requires a foresighted choice of the sample of variables. It is obviously absurd to expect to get any determinate rotation of a certain factor $\mathrm{X}$ if we have chosen the variables in the study such that probably all of them will have some significant loading on $\mathrm{X}$. (p. 112)

In this regard, do the present taxometric procedures differ from the use of simple structure factor analysis? To find a real source of influence through the application of the taxometric methods, there must be, underlying a set of phenotypic variables, a real source of influence that is a dichotomous class variable. There also must be identifiable phenotypic variables that generally discriminate between the two classes. Finally, the phenotypic variables identified must not highly correlate within the two classes. Clearly, finding a real source of influence underlying a set of phenotypic variables using the taxometric methods requires a modicum of fortuitousness no less than does a successful application of factor analysis.

But, we quickly add, there is one significant difference. When this modicum of fortuitousness is not forthcoming, the factor-analytic simple structure solution itself does not tell us that the real underlying sources of influence are not to be found in the rotated solution. The method itself does not distinguish between successful and unsuccessful finds. Thus, as a result, one may be led to incorrectly believe that real sources of influence have been found in the rotated solution (or that no real influences, outside of those represented in the rotated solution, exist).

In contrast, the taxometric methods inform their users that they have not found a real source of influence when they have not received that modicum of fortuitousness-when no real class variable exists, when the phenotypic variables they have selected are not sufficiently influenced by the class variable, or when the phenotypic variables intercorrelate substantially within the classes. In these circumstances, the taxometric procedures will not yield the predicted peaked covariance curves, the consistent base rate estimates, and a classification scheme that will increase predictability of external criterion variables (see Meehl, 1978, 1979; Meehl \& Golden, 1982). 
Thus, the taxometric methods do allow their users to distinguish unsuccessful from successful finds.

Of course, we do not mean to suggest that taxometric methods be applied indiscriminately. Clearly, they are most appropriately applied when there exists some reason to believe that a specific class variable exists. Also, we do not mean to suggest that factor analysis and rotation to simple structure should never be used. Even if and when rotation to simple structure does not reveal real underlying sources of influence, rotation to simple structure generally does facilitate descriptive interpretability of the factors. For pursuing purely instrumental ends (e.g., atheoretical prediction), researchers may require no more than the convenience of ease of interpretability that simple structure offers. At the same time, however, researchers should be aware that rotation to simple structure (or, in fact, rotation to any structure selected on the basis of an a priori assumption) cannot be counted on to locate nature's true joints. Indeed, the following statement made by Cronbach and Meehl (1955) is as true today as it was the day it was written: "Factors may or may not be weighted with surplus meaning. Certainly when they are regarded as 'real dimensions' a great deal of surplus meaning is implied, and the interpreter must shoulder a substantial burden of proof" (p. 63).

\section{Prevalence of Class Variables in Personality}

At the beginning of this article, we noted that there exists in personology a widespread, implicit if not explicit, presumption that differences between people are differences in degree, not differences in kind. We argued that many of the arguments against the existence of discrete class variables in personality are not applicable when class variables are explicated genetically - as class variables that "carve nature at its joints"-rather than phenetically. Still, we admitted, there had yet to be demonstrated the existence of a class variable (with the exception of biological sex and psychopathologies of relatively low incidence) that exerted important influences on social behavior. We believe that we are now in a position to claim that one exception has been demonstrated-self-monitoring does give every indication of existing as a discretely distributed class variable.

Discreteness in personality, then, is possible and can be demonstrated to exist. However, by taking seriously the existence of class variables in personality, a new question arises. How widespread are true class variables in personality? How common are personality etiologies involving specific dichotomous factors or threshold effects? It is, of course, possible that true class variables are abundant, that discreteness in personality development and organization are as much the rule as the exception. But we are well aware that the identification of even a single class variable with important influences on social behavior (excepting biological sex) may come as something of a surprise to many personologists. Surely, much past observation, from which discrete variables have been quite absent, speaks otherwise. But then, it may be that we have too long used yardsticks that have not allowed us to detect the discreteness that exists.

Of course, it is also possible that discretely distributed class variables are rare phenomena in personality. In this respect, self-monitoring propensities may reside in select company. This possible rarity, however, surely should not blind us to seeing the value of identifying a class variable where a class variable truly exists. In the case of self-monitoring, identification of a class variable has led us to ask and pursue fundamentally different questions and research strategies, as well as to develop radically different conceptual frameworks of etiology and development. So too with the case of any other class variable in personality would one be compelled by its identification to formulate and pursue different questions and research strategies. Only by recognizing the class variables that exist will these questions be asked and answered. Only by asking and answering these questions will it be possible to discover discreteness where it truly exists in personality. Only by discovering the domains of personality where true discreteness exists in personality will it be possible "to carve nature at its joints." And, not incidentally, taking seriously the existence of discrete classes in personality may even make it possible to take seriously claims of "There are two types of people in the world." 


\section{References}

Ajzen, I., Timko, C., \& White, J. B. (1982). Selfmonitoring and the attitude-behavior relation. Journal of Personality and Social Psychology, 43, 426-435.

Anderberg, M. R. (1973). Cluster analysis for applications. New York: Academic.

Ashlock, P. D. (1979). An evolutionary systematist's view of classification. Systematic Zoology, 28, 441-450.

Bandura, A., \& Walters, R. H. (1963). Social learning and personality development. New York: Holt, Rinehart \& Winston.

Becherer, R. C., \& Richard, L. M. (1978). Self-monitoring as a moderator of consumer behavior. Journal of Consumer Research, 5, 159-162.

Bem, D. J. (1972). Self-perception theory. In L. Berkowitz (Ed.), Advances in experimental social psychology (Vol. 6, pp. 1-62). New York: Academic Press.

Blashfield, R. K. (1976). Mixture model tests of cluster analysis: Accuracy of four agglomerative hierarchical models. Psychological Bulletin, 83, 377-388.

Block, J. H. (1976). lssues, problems, and pitfalls in assessing sex differences: A critical review of the psychology of sex differences. Merrill-Palmer Quarterly, 22, 283-308.

Bock, W. J. (1973). Philosophical foundations of classical evolutionary classification. Systematic Zoology, 22, 375-392.

Briggs, S. R., Cheek, J. M., \& Buss, A. H. (1980). An analysis of the Self-Monitoring Scale. Journal of Personality and Social Psychology, 38, 679-686.

Caldwell, D. F., \& O'Reilly, C. A. (1982). Responses to failure: The effects of choice and responsibility on impression management. Academy of Management Journal, 25, 121-136.

Carter, C. O. (1969). Genetics of common disorders. British Medical Bulletin, 25, 52-57.

Cattell, R. B. (1966). The scree test for the number of factors. Multivariate Behavioral Research, I, 140-160.

Cattell, R. B. (1978). The scientific use of factor analysis in behavioral and life sciences. New York: Plenum.

Cattell, R. B. (1979). The structure of personality in its environment. New York: Springer.

Cheek, J. M. (1982). Aggregation, moderator variables, and the validity of personality tests: A peer-rating study. Journal of Personality and Social Psychology, 43, 1254-1269.

Cronbach, L. J., \& Meehl, P. E. (1955). Construct validity in psychological tests. Psychological Bulletin, 52, 281302.

Danheiser, P. R., \& Graziano, W. G. (1982). Self-monitoring and cooperation as a self-presentational strategy. Journal of Personality and Social Psychology, 42, 497505.

Dworkin, R. H. (1977, August). Genetic influences on cross-situational consistency. Paper presented at the Second International Congress on Twin Studies, Washington, DC.

Everitt, B. S. (1974). Cluster analysis. London: Heinemann.

Eysenck, H. J. (1950). Criterion analysis-an application of the hypothetico-deductive method of factor analysis. Psychological Review, 57, 38-53.

Eysenck, H. J. (1953). The structure of human personality. London: Methuen.
Eysenck, H. J. (1969). Nature and history of human typology. In H. J. Eysenck \& S. B. G. Eysenck (Eds.), Personality structure and measurement (pp. 3-137). London: Routledge \& Kegan Paul.

Eysenck, H. J., \& Eysenck, S. B. G. (1968). Manual for the Eysenck Personality Inventory. San Diego: Educational and Industrial Testing Service.

Falconer, D. S. (1967). The inheritance of liability to diseases with variable ages of onset, with particular reference to diabetes mellitus. Annals of Human Genetics, 31, 1-20.

Farris, J. S. (1979). On the naturalness of phylogenetic classification. Systematic Zoology, 28, 200-214.

Fisher, R. A. (1946). Statistical methods for research workers (10th ed.). Edinburgh, Scotland: Oliver \& Boyd.

Furnham, A. \& Capon, M. (1983). Social skills and selfmonitoring processes. Personality and Individual Differences, $4,171-178$.

Gabrenya, W. K., Jr., \& Arkin, R. M. (1980). Factor structure and factor correlates of the Self-Monitoring Scale. Personality and Social Psychology Bulletin, 6. 13-22.

Gingerich, P. D. (1979). Paleontology, phylogeny, and classification: An example from the mammalian fossil record. Systematic Zoology, 28, 451-464.

Golden, R. R. (1982). A taxometric model for the detection of a conjectured latent taxon. Multivariate Behavioral Research, 17, 389-416.

Golden, R. R., \& Meehl, P. E. (1973). Detecting clinical taxa, V: A Monte Carlo study of the maximum covariance method and associated consistency tests (Report No. PR-73-4). Minneapolis: University of Minnesota, Reports from the Research Laboratories of the Department of Psychiatry.

Golden, R. R., \& Meehl, P. E. (1979). Detection of the schizoid taxon with MMPI indicators. Journal of $A b$ normal Psychology, 88, 217-233.

Grove, W. M. (1983). The numerical taxonomy of endogenous depression. Unpublished doctoral dissertation, University of Minnesota, Minneapolis.

Guilford, J. P., \& Zimmerman, W. S. (1963). Some variable-sampling problems in the rotation of axes in factor analysis. Psychological Bulletin, 60, 289-301.

Hall, G. S. (1907). Aspects of child's life and education. New York: Appleton.

Hays, W. L. (1973). Statistics for the social sciences (2nd ed.). New York: Holt, Rinehart \& Winston.

Hempel, C. G. (1965). Fundamentals of taxonomy. In C. G. Hempel, Aspects of scientific explanation and other essays in the philosophy of science (pp. 137154). New York: Free Press.

Henderson, N. D. (1982). Human behavior genetics. Annual Review of Psychology, 33, 403-440.

Hogan, R. (1983). A socioanalytic theory of personality. In M. M. Page (Ed.), Nebraska Symposium on Motivation: Vol. 30. Personality-current theory and research (pp. 55-89). Lincoln: University of Nebraska Press.

Horgan, D. (1981). Rate of language acquisition and noun emphasis. Journal of Psycholinguistic Research, $10,629-640$.

Ickes, W. J., Layden, M. A., \& Barnes, R. D. (1978). Objective self-awareness and individuation: An empirical link. Journal of Personality, 46, 146-161. 
Jackson, D. N. (1971). Structured personality tests: 1971. Psychological Review, 78, 229-248.

Jackson, D. N. (1974). Personality Research Form mamual New York: Research Psychologists Press.

Jung, C. G. (1923). Psychological types (H. G. Baynes, Trans.). New York: Harcourt, Brace. (Original work published 1921)

Kohlberg, L. (1969). Stage and sequence: The cognitivedevelopmental approach to socialization. In D. A. Goslin (Ed.), Handbook of socialization theory and research (pp. 347-480). New York: Rand-McNally.

Krauss, R. M., Geller, V., \& Olson, C. (1976, September). Modalities and cues in perceiving deception. Paper presented at the meeting of the American Psychological Association, Washington, DC.

Kretschmer, E. (1948). Körperban und charakter [Physique and character]. Berlin: Springer.

Kuiper, F. K., \& Fisher, L. (1975). A Monte Carlo comparison of six clustering procedures. Biometrics, $31,777-783$.

Kulik, J. A., \& Taylor, S. E. (1981). Self-monitoring and the use of consensus information. Journal of Personality, 49, 75-84.

Langmuir, I. (1943). Science, common sense, and decency. Science, 97, 1-7.

Lazarsfeld, P. F. (1950). The logical and mathematical foundation of latent structure analysis. In S. A. Stouffer et al., Measurement and prediction (pp. 362-412). Princeton, NJ: Princeton University Press.

Lippa, R. (1976). Expressive control and the leakage of dispositonal introversion-extraversion during roleplayed teaching. Journal of Personality, 44, 541-559.

Lippa, R. (1978a). Expressive control, expressive consistency, and the correspondence between behavior and personality. Journal of Personality, 46, 438-461.

Lippa, R. (1978b, September). Self-presentation and expressive display of personality. Paper presented at the annual meeting of the American Psychological Association, Toronto.

Lippa, R., \& Mash, M. (1979) The effects of selfmonitoring and self-reported consistency of personality statements made by strangers and intimates. Unpublished manuscript, California State University, Fullerton.

Lippa, R., Valdez, E., \& Jolly, A. (1979, September). Self-monitoring and the consistency of masculinityfemininity cues. Paper presented at the annual meeting of the American Psychological Association, New York.

Loevinger, J. (1957). Objective tests as instruments of psychological theory. Psychological Reports, 3. 635694.

London, I. D. (1946). Some consequences for history and psychology of Langmuir's concepts of convergence and divergence of phenomena. Psychological Review. 53, 170-188.

Lord, F. M., \& Novick, M. R. (1968). Statistical theories of mental test scores. Reading, MA: Addison-Wesley.

Lutsky, N., Woodworth, W., \& Clayton, S. (1980, May). Actions-attitudes-actions: A multivariate, longitudinal study of attitude-behavior consistency. Paper presented at the annual meeting of the Midwestern Psychological Association, St. Louis, MO.

Maccoby, E. E., \& Jacklin, C. N. (1974). The psychology of sex differences. Stanford, CA: Stanford University Press.
Maxwell, A. E. (1971). Multivariate statistical methods and classification problems. British Journal of Psychiatry, 119. 121-127.

Mayr, E. (1969). Principles of systematic zoology. New York: McGraw-Hill.

McCann, D., \& Hancock, R. D. (1983). Self-monitoring in communicative interactions: Social cognitive consequences of goal-directed message modification. Journal of Experimental Social Psychology, 19, 109-121.

McNeill, J. (1979). Purposeful phenetics. Systematic Zaology, 28, 465-482.

Meehl, P. E. (1962) Schizotaxia, schizotypy, schizophrenia. American Psychologist, 17, 827-838.

Meehl, P. E. (1965). Detecting latent clinical taxa by fallible quantitative indicators lacking an accepted criterion (Report No. PR-65-2). Minneapolis: University of Minnesota, Reports from the Research Laboratories of the Department of Psychiatry.

Meehl, P. E. (1968). Detecting latent clinical taxa, II: A simplified procedure, some additional hilmax locators, a single-indicator method, and miscellaneous theorems (Report No. PR-68-4). Minneapolis: University of Minnesota, Reports from the Research Laboratories of the Department of Psychiatry.

Meehl, P. E. (1972). Reactions, reflections, projections. In J. Butcher (Ed.), Objective personality assessment: Changing perspectives (pp. 131-189). New York: Academic Press.

Meehl, P. E. (1973). MAXCOV-HITMAX: A taxonomic search method for loose genetic syndromes. In P. E. Meehl, Psychodiagnosis: Selected papers (pp. 200224). Minneapolis: University of Minnesota Press.

Meehl, P. E. (1977). Specific etiology and other forms of strong influence: Some quantitative meanings. Journal of Medicine and Philosophy, 2, 33-53.

Meehl, P. E. (1978). Theoretical risks and tabular asterisks: Sir Karl, Sir Ronald, and the slow progress of soft psychology. Journal of Consulting and Clinical Psychology, 46, 806-834.

Meehl, P. E. (1979). A funny thing happened on the way to the latent entities. Journal of Personality Assessment, 43, 563-581.

Meehl, P. E., \& Golden, R. R. (1982). Taxometric methods. In J. N. Butcher \& P. C. Kendall (Eds.), The handbook of research methods in clinical psychology (pp. 127-181). New York: Wiley.

Mendelsohn, G. A., Weiss, D. S., \& Feimer, N. R. (1982). Conceptual and empirical analysis of the typological implications of patterns of socialization and femininity. Journal of Personality and Social Psychology, 42, 11571170.

Mischel, W. (1976). Introduction to personality (2nd ed.). New York: Holt, Rinehart \& Winston.

Mojena, R. (1977). Hierarchical grouping methods and stopping rules: An evaluation. Computer Journal, 20, 359-363.

Murphy, E. A. (1964). One cause? Many causes? The argument from a bimodal distribution. Journal of Chronic Diseases, 17, 301-324.

Mussen, P. H., Conger, J. J., \& Kagan, J. (1963). Child development and personality (2nd ed.). New York: Harper \& Row.

Myers, I. B. (1962). The Myers-Briggs type indicator manual. Princeton, NJ: Educational Testing Service. 
Nelson, K. (1973). Structure and strategy in learning how to talk. Monographs of the Society for Research in Child Development, 38 (I-2, Serial No. 149).

Nelson, K. (1981). Individual differences in language development: Implications for development and language. Developmental Psychology, 17, 170-187.

Overall, J. (1964). Note on the scientific status of factors. Psychological Bulletin, 61, 270-276.

Paulhus, D. (1982). Individual differences, self-perception, and cognitive dissonance: Their concurrent operation in forced compliance. Journal of Personality and Social Psychology, 43, 838-852.

Piaget, J. (1965). The child's conception of the world. Totowa, NJ: Littlefield, Adams.

Plomin, R., DeFries, J. C., \& Loehlin, J. C. (1977). Genotype-environment interaction and correlation in the analysis of human behavior. Psychological Bulletin, 84, 309-322.

Plomin, R., DeFries, J. C., \& McClearn, G. E. (1980). Behavioral genetics: A primer. San Francisco: W. H. Freeman.

Ramer, A. (1976). Syntactic styles in emerging language. Journal of Child Language, 3, 49-62.

Rarick, D. L., Soldow, G. F., \& Geiser, R. S. (1976). Self-monitoring as a mediator of conformity. Central States Speech Journal, 27, 267-271.

Riggio, R. E., \& Friedman, H. S. (1982). The inter relationships of self-monitoring factors, personality traits, and nonverbal social skills. Journal of Nonverbal Behavior, 7, 33-45.

Ross, M., McFarland, C., \& Fletcher, G. J. O. (1981). The effect of attitude on the recall of personal histories. Journal of Personality and Social Psychology, 40, 627634.

Rummel, R. J. (1970). Applied factor analysis. Evanston, IL: Northwestern University Press.

Ruse, M. (1973). The philosophy of biology. London: Hutchinson.

Shaffer, D. R., Smith, J. E., \& Tomarelli, M. (1982). Selfmonitoring as a determinant of self-disclosure reciprocity during the acquaintance process. Journal of Personality and Social Psychology. 43, 163-175.

Shaw, M. E., \& Costanzo, P. R. (1982). Theories of social psychology (2nd ed.). New York: McGraw-Hill.

Siegman, A. W., \& Reynolds, M. A. (1983). Self-monitoring and speech in feigned and unfeigned lying. Journal of Personality and Social Psychology, 45, 13251333.

Sneath, P. H. A., \& Sokal, R. R. (1973). Numerical taxonomy. San Francisco: W. H. Freeman.

Snyder, M. (1974). Self-monitoring of expressive behavior. Journal of Personality and Social Psychology, 30, 526537.

Snyder, M. (1979a). Cognitive, behavioral, and interpersonal consequences of self-monitoring. In P. Pliner, K. R. Blankstein, \& I. M. Spigel (Eds.), Advances in the study of communication and affect: Vol. 5. Perception of emotion in self and others (pp. 181-201). New York: Plenum.

Snyder, M. (1979b). Self-monitoring processes. In L. Berkowitz (Ed.), Advances in experimental social psychology (Vol. 12, pp. 85-128). New York: Academic Press.
Snyder, M. (1981). On the influence of individuals on situations. In N. Cantor \& J. F. Kihlstrom (Eds.), Personality, cognition, and social interaction (pp. 309329). Hillsdale, NJ: Erlbaum.

Snyder, M. (1983a). The influence of individuals on situations: Implications for understanding the links between personality and social behavior. Journal of Personality, 51, 497-516.

Snyder, M. (1983b, May). The self in action. Paper presented at the annual meeting of the Midwestern Psychological Association, Chicago.

Snyder, M., Berscheid, E., \& Glick, P. (1985). Focusing on the exterior and the interior: Two investigations of the initiation of personal relationships. Journal of Personality and Social Psychology, 48, 427-439.

Snyder, M., \& Campbell, B. (1982). Self-monitoring: The self in action. In J. Suls (Eds.), Psychological perspectives on the self (Vol. 1, pp. 185-207). Hillsdale, NJ: Erlbaum.

Snyder, M., \& Cantor, N. (1980). Thinking about ourselves and others: Self-monitoring and social knowledge. Journal of Personality and Social Psychology, 39, 222234.

Snyder, M., \& Gangestad, S. (1982). Choosing social situations: Two investigations of self-monitoring processes. Journal of Personality and Social Psychology. 43. $123-135$.

Snyder, M., Gangestad, S., \& Simpson, J. A. (1983). Choosing friends as activity partners: The role of selfmonitoring. Journal of Personality and Social Psychology, 45, 1061-1072.

Snyder, M., \& Ickes, W. (1985). Personality and social behavior. In G. Lindzey \& E. Aronson (Eds.), Handbook of social psychology (3rd ed., pp. 883-948). New York, NY: Random House.

Snyder, M., \& Kendzierski, D. (1982a). Acting on one's attitudes: Procedures for linking attitude and behavior. Journal of Experimental Social Psychology, 18, 165183.

Snyder, M., \& Kendzierski, D. (1982b). Choosing social situations: A strategy for generating correspondence between attitudes and behavior. Journal of Personality, $50.280-295$.

Snyder, M., \& Monson, T. C. (1975). Persons, situations, and the control of social behavior. Journal of Personality and Social Psychology, 32, 637-644.

Snyder, M., \& Simpson, J. A. (1984). Self-monitoring and dating relationships. Journal of Personality and Social Psychology, 47, 1281-1291.

Snyder, M., \& Swann, W. B. (1976) When actions reflect attitudes: The politics of impression management. Journal of Personality and Social Psychology, 34, 1034 1042.

Snyder, M., \& Tanke, E. D. (1976). Behavior and attitude: Some people are more consistent than others. Journal of Personality, 44, 510-517.

Sparacino, J., Ronchi, D., Bagley, T. K., Flesch, A. L., \& Kuhn, J. W. (1983). Self-monitoring and blood pressure. Journal of Personality and Social Psychology, 44, 365-375.

Starr, S. (1974). The relationship of single words to twoword sentences. Child Development, 46, 701-708.

Sypher, B. D., \& Sypher, H. H. (1983). Self-monitoring and perceptions of communication ability in an orga- 
nizational setting. Personality and Social Psychology Bulletin, 9, 297-304.

Thurstone, L. L. (1947). Multiple factor analysis. Chicago: University of Chicago Press.

Tobey, E. L., \& Tunnell, G. (1981). Predicting our impressions on others: Effects of public self-consciousness and acting, a self-monitoring subscale. Personality and Social Psychology Bulletin, 7, 661-669.

Tukey, J. W. (1977). Exploratory data analysis. Reading, MA: Addison-Wesley.

Tunnell, G. (1980). Intraindividual consistency in personality assessment: The effect of self-monitoring. Journal of Personality, 48, 220-232.

Tybout, A. M., \& Scott, C. A. (1983). Availability of well-defined internal knowledge and the attitude formation process: Information aggregation versus selfperception. Journal of Personality and Social Psychology, 44, 474-491.

Tyler, L. E. (1965). The psychology of individual differences (3rd ed.). Englewood Cliffs, NJ: Prentice-Hall.
Waddington, C. H. (1957). The strategy of the genes. New York: Macmillan.

Ward, J. H. (1963). Hierarchical grouping to optimize an objective function. Journal of the American Statistical Association, 58, 236-244.

Werner, H. (1957). The concept of development from a comparative and organismic point of view. In $D$. Harris (Ed.), The concept of development (pp. 125161). Minneapolis: University of Minnesota Press.

Wolf, D., \& Gardner, H. (1979). Style and sequence in early symbolic play. In N. Smith \& M. Franklin (Eds.), Symbolic functioning in childhood (pp. 117-138). Hillsdale, NJ: Erlbaum.

Zanna, M. P., Olson, J. M., \& Fazio, R. H. (1980). Attitude-behavior consistency: An individual difference perspective. Journal of Personality and Social Psychology, 38, 432-440.

Zuckerman, M., \& Reis, H. T. (1978). A comparison of three models for predicting altruistic behavior. Journal of Personality and Social Psychology, 36, 498-510.

\section{Appendix}

\section{Predicting a Peaked Covariance Curve}

Consider the two items, $i$ and $j$, selected from the set of the eight conjectured items. If two classes exist within any sample (for convenience, let us call them the class of highs and the class of lows), it is an algebraic truth that the sample covariance between the two indicators is equal to the sum of three terms:

$$
\operatorname{cov}(i j)=p \operatorname{cov}_{\mathbf{H}}(i j)+q \operatorname{cov}_{\mathbf{L}}(i j)+p q \Delta \bar{i} \Delta \bar{j},
$$

where

$p=$ the proportion of highs in the sample;

$q=$ the proportion of lows in the sample;

$\operatorname{cov}_{\mathrm{H}}(i j)=$ the covariance between the indicators within the subsample of highs;

$\operatorname{cov}_{\mathbf{L}}(i j)=$ the covariance between the indicators within the subsample of lows;

$\Delta \bar{i}=$ the difference between the mean $i$ scores within the subsample of highs and within the subsample of lows; and

$\Delta \bar{j}=$ the difference between the mean $j$ scores within the subsample of highs and within the subsample of lows.

We have ideally assumed that the two indicators are independent within the classes and thus that the within-class covariances are equal to zero. If this assumption holds, then the only source of covariance within the total sample will be the third term in the expression above. Thus,

$$
\operatorname{cov}(i j)=p q \Delta \bar{i} \Delta \bar{j}
$$

Of course, before we have started we do not know what $p$ and $q$ are for any given sample, nor do we have estimates of $\Delta \bar{i}$ or $\Delta \bar{j}$ for any given population, nor, in fact, do we know whether two classes do actually exist. As the above formula reveals, however, if two classes do exist (and when $\Delta \bar{i}$ and $\Delta \bar{j}$ are held relatively constant), we expect the covariance between $i$ and $j$ in a sample to be some function of the relative proportions of the two classes, $p$ and $q$. Thus, for instance, if we could somehow select a pure sample of high selfmonitoring individuals, we would expect $\operatorname{cov}(i j)$ to be near zero because $\operatorname{cov}(i j)=(1.00)(.00) \Delta \bar{i}$ $\Delta \bar{j}=0$. Similarly, if we could select a pure sample of low self-monitoring individuals, we would also expect cov $(i j)$ to be near zero. Suppose now we select a sample of $1 / 4$ of one class and $3 / 4$ of the other. Then we would expect cov (ij) to be other than zero because $(.25)(.75) \Delta i \Delta j=(.1875)$ $\Delta \vec{i} \vec{j}$. Moreover if $i$ and $j$ are keyed in the conjectured direction, as we assume here, then we would expect this value to be positive. And if we select a sample of $40 \%$ of one class and $60 \%$ of the other class, we would expect some larger value still because (.40) (.60) $\Delta \bar{i} \Delta \bar{j}>.1875 \Delta \bar{i} \Delta \bar{j}$. Finally, it is a simple mathematical truth that because the product $p q$ is maximal when there exist equal numbers from each class in the sample (i.e., $p=$ $q=1 / 2$ ), as long as $\Delta \bar{i}$ and $\Delta \bar{j}$ are held constant, cov $(i j)$ is also expected to be maximal when $p=$ $q=1 / 2$. 
Given this fact, we can create a powerful bootstraps effect (Cronbach \& Meehl, 1955). For our item pair, $i$ and $j$, we take the remaining six items of our conjectured eight-item pool and construct a 7-point scale (with values ranging from 0-6). If, as we have already assumed, these six items discriminate between the classes, then this small scale also discriminates between the classes. And, if our items $i$ and $j$ do not highly correlate with any of the six items within the classes, as we have also already assumed, then $i$ and $j$ will not correlate very highly with the small scale within the classes. Let us now use this 7-point scale to select different subsamples, each corresponding to the set of individuals who obtained a given score on the scale. If the above conditions hold (once again, testable for fit afterwords) and if two classes really do exist, then the seven different subsamples we have created should have a different $p$ and $q$. The seven subsamples should, however, have similar $\Delta \bar{i}$ and $\Delta \bar{j}$. (These latter values, in fact, should be similar to $\Delta \bar{i}$ and $\Delta \bar{j}$ for the entire sample.)
If two classes exist and if the smaller of the two classes is large enough so that the latent frequency distributions on the 7-point scale cross, then there will exist a scale value within which $p \sim q \sim 1$ / 2. Moreover, if the latent frequency distributions are monomodal and are not too unequal in size (so that the smaller of $p$ and $q$ equals at least .2), this value will be located somewhere toward the middle of the scale. Samples associated with values toward the extremes are expected to be composed of more disparate $p$ and $q$. Given our previous results, this expectation yields the following prediction: If a class variable underlies responses to the items as conjectured, the seven sample covariances between $i$ and $j$ plotted as a function of the values on the 7-point scale should be peaked; maximal toward the middle and nearer to zero toward the extremes.

Received March 28, 1984

Revision received November 28,1984

\section{Special Call for Papers on Psychology and Aging}

The Psychology and Aging journal is gearing up for its first year of publication in 1986. Manuscripts have been received in the editorial office for a number of months, but more than $50 \%$ of the original submissions have been experimental. The Editor, M. Powell Lawton, and the Associate Editor, Donald H. Kausler, wish to emphasize that Psychology and Aging will be a broad-ranging publication, and manuscripts from all areas of psychology are desired.

Papers on all aspects of issues related to psychology and aging are encouraged. As the proposed editorial policy statement outlines:

Psychology and Aging publishes original articles on adult development and aging. Such original articles include reports of research, which may be applied, biobehavioral, clinical, educational, experimental (laboratory, field, or naturalistic studies), methodological, or psychosocial. Although the emphasis is on original research investigations, occasional theoretical analyses of research issues, practical clinical problems, or policy may appear, as well as critical reviews of a content area in adult development and aging. Clinical case studies that have theoretical significance are also appropriate. Brief reports are acceptable with the author's agreement not to submit a full report to another journal; a 75-100 word abstract plus 48-space lines of text and references constitute absolute limitations on space for such brief reports.

Manuscripts should be directed to:

M. Powell Lawton

Philadelphia Geriatric Center

5301 Old York Road

Philadelphia, Pennsylvania 19141 